\title{
HIV patients retention and attrition in care and their determinants in Ethiopia: a systematic review and meta-analysis
}

\author{
Nurilign Abebe Moges ${ }^{1,2^{*}}$ (D) Adesina Olubukola ${ }^{3}$, Okunlola Micheal ${ }^{3}$ and Yemane Berhane ${ }^{4}$
}

\begin{abstract}
Background: There is paucity of evidence on the magnitude of HIV patients' retention and attrition in Ethiopia. Hence, the aim of this study was to determine the pooled magnitude of HIV patient clinical retention and attrition and to identify factors associated with retention and attrition in Ethiopia.

Methods: Systematic review and meta-analysis were done among studies conducted in Ethiopia using the Preferred Reporting Items for Systematic Reviews and Meta-Analyses (PRISMA) guideline. Both published and unpublished studies conducted from January 1, 2005 to June 6th, 2019 were included. Major databases and search engines such as Google Scholar, PUBMED, African Journals Online (AJOL) and unpublished sources were searched to retrieve relevant articles. Data were assessed for quality, heterogeneity and publication bias. Analysis was conducted using STATA version 14 software.
\end{abstract}

Result: From a total of 45 studies 546,250 study participants were included in this review. The pooled magnitude of retention in care among HIV patients was $70.65 \%(95 \% \mathrm{Cl}, 68.19,73.11)$. The overall magnitude of loss to follow up $15.17 \%(95 \% \mathrm{Cl}, 11.86,18.47)$, transfer out $11.17 \%(95 \% \mathrm{Cl}, 7.12,15.21)$ and death rate were $6.75 \%(95 \% \mathrm{Cl}, 6.22$, 7.27). Major determinants of attrition were being unmarried patient (OR 1.52, 95\% Cl: 1.15-2.01), non-disclosed HIV status (OR 6.36, 95\% Cl: 3.58-11.29), poor drug adherence (OR 6.60, 95\% Cl: 1.41-30.97), poor functional status (OR 2.11 , 95\% Cl: 1.33-3.34), being underweight (OR 2.21, 95\% Cl: 1.45-3.39) and advanced clinical stage (OR 1.85, 95\% Cl: 1.36-2.51). Whereas absence of opportunistic infections (OR $0.52,95 \% \mathrm{Cl}: 0.30-0.9$ ), normal hemoglobin status (OR 0.29, 95\% Cl: 0.20-0.42) and non-substance use (OR 95\% Cl: 0.41, 0.17-0.98) were facilitators of HIV patient retention in clinical care.

Conclusion: The level of retention to the care among HIV patients was low in Ethiopia. Socio-economic, clinical, nutritional and behavioral, intervention is necessary to achieve adequate patient retention in clinical care.

Keywords: Retention, Attrition, HIV patient, Systematic review, Ethiopia

\footnotetext{
* Correspondence: nure113@gmail.com

'Department of Public Health, College of Health Sciences, Debre Markos University, Debre Markos, Ethiopia

${ }^{2}$ Pan African University, Life and Earth Sciences Including Health and Agriculture Institute (PAULESI), University of Ibadan, Ibadan, Nigeria Full list of author information is available at the end of the article
} 


\section{Background}

Globally, 36.7 million people were living with Human Immunodeficiency Virus (HIV) in 2016 [1]. The United Nations Programme on HIV/AIDS (UNAIDS) 90-90-90 target states that $90 \%$ of people living with HIV should know their status, $90 \%$ of people living with HIV who know their status should be on treatment, and $90 \%$ of people on treatment should be virally suppressed. A record 19.5 million people were accessing antiretroviral therapy in 2017, and for the first time, more than half of all people living with HIV are on treatment [2].

In Ethiopia, Antiretroviral treatment (ART) began in 2003 and free ART was launched in January 2005. In 2016 , only $67 \%$ of HIV positive people are believed to know their status. Additionally, the treatment coverage of all HIV positive people was $59 \%$ and only $51 \%$ of all HIV positive people on highly active antiretroviral therapy (HAART) had viral suppression [1]. In 2017, an estimated 738,976 Ethiopians were living with HIV and all of them were eligible for ART treatment. However, it was reported that only 426,000 were taking ARV in the same year [3].

The estimated 36-month retention from 2008 to 2013 was; $65 \%$ in Africa, $80 \%$ in Asia, and 64\% in Latin America and the Caribbean [4]. In low and middle income countries HIV patient retention at 36 months on treatment averages $65-70 \%$ [4]. Patient retention in care is a challenge in many African countries [5, 6]. Similarly, in various regions of Ethiopia, during the pre-ART era, about one third of HIV positive people receiving clinical care were lost to follow up [7, 8]. Retention in care within 12 month of treatment initiation varies from 83 to $94 \%$ in Ethiopia [9].

Qualitative studies in Addis Ababa, Bahir Dar and Gondar, Ethiopia, revealed that fear of stigma, care dissatisfaction, use of holy water, fasting, and economic constraints discouraged retention in care. Whereas social support and restored health and functional ability motivated retention $[10,11]$.

Though Ethiopia has improved patient retention from 2005 to 2013 [12], still there are large number of patients that discontinue from treatment [13]. Unlike other regions of the world [4], there is paucity of evidence on the rate of attrition among HIV positive patient in Ethiopia. A systematic review and meta-analysis on ART treatment discontinuation of HIV patients in Ethiopia indicated various factors are responsible for treatment discontinuation [13]. However, the study was limited to only 9 papers and only three regions out of nine regions of the country. At the same time, this previous study did not include pooled incidence and prevalence of loss to follow up, death and transfer out [13]. In addition, the study does not show the magnitude of patient retention and attrition. In view of this, we decided to investigate the retention, attrition and its determinants at national level. Patient attrition includes loss to follow up (LTF), death (D) and transfer out (TO) which is the official transfer of the patient to another clinic. Therefore, this study aimed to determine the pooled magnitude of HIV patients' clinical retention, attrition and identify factors associated with retention and attrition.

\section{Methods \\ Study design}

Systematic review and meta-analysis was done using studies conducted in English language in Ethiopia. Preferred Reporting Items for Systematic Reviews and Meta-Analyses (PRISMA) [14] was strictly followed during search of studies and analysis process.

\section{Eligibility criteria}

We included studies conducted on adult HIV positive individuals' retention in HIV care in Ethiopia. Studies that reported lost to follow up, defaulters and treatment discontinuation, transfer out and death were included. Studies that used any length of follow up period were eligible for this review. There was no restriction based on study designs of primary studies except systematic review and meta-analysis. Both published and unpublished primary studies from the start of ART program in January 2005 in Ethiopia to last date of literature review on June 6, 2019 were included. The reason for restriction of study period was that the first article in Ethiopia about HIV patients' retention in clinical care data were collected in 2005 and published in 2008 and the last date of literature review search was on Jun 6, 2019. Moreover, qualitative studies which didn't report quantitative outcomes of interest were excluded.

\section{Search strategy}

Published research was identified through a systematic search of PubMed, Google Scholar and the African Journals Online (AJOL). Information were retrieved from online published data sources and unpublished thesis works. Online databases include PubMed, Google scholar and African Journals online (AJOL). We used search terms in PubMed as (retention) OR attrition) AND HIV) OR AIDS) AND patients) OR positive people) AND Ethiopia). Moreover, keywords for review included; retention, attrition, loss to follow up, dead, discontinuation, defaulters and treatment outcomes of ART in Ethiopia and were used to search additional articles. We audited the references of all articles which deemed important for our outcomes of interest. Moreover, we searched for unpublished works in the postgraduate library of Debre Markos University and other universities institutional repositories. 


\section{Study selection and quality appraisal}

Studies were evaluated using title, abstract and full text. Studies that used retrospective follow up design were included only if full cohort assessment report was obtained. Quality was assessed using Critical Appraisal and Assessment of Methodological Quality of Studies for Systematic Review and Meta-analysis of Observational Epidemiological Studies Reporting Prevalence and $\mathrm{Cu}$ mulative Incidence Data [15]. Two authors independently assessed the quality of the studies. Where disagreement occurred, studies were discussed until consensus was reached. Studies were assessed on nine dimensions and for each dimension the authors would indicate that the criteria was met or not met. In cases where there was insufficient information to determine the study could be graded "unclear." The following criteria were used: 1 . was the sample frame appropriate to address the target population? 2. Were study participants sampled in appropriate way? 3. Was the sample size adequate? 4 . Were the study subjects and the setting described in detail? 5. Was the data analysis conducted with sufficient coverage of the identified sample? 6 . Were valid methods used for the identification of the condition? 7. Was the condition measured in a standard, reliable way for all participants? 8. Was there an appropriate statistical analysis? 9. Was the response rate adequate, and if not, was the low response rate managed appropriately [15]. To be included in the meta-analysis, articles were required to meet at least 5 of the nine criteria. Quality appraisal table can be found in (Additional file 1).

\section{Data extraction}

Relevant data was extracted from eligible studies and entered into Microsoft Excel. Data collected included authors, year of publication, study period, study area, sample size, study design, our outcome of interest (retention, loss to follow up, transfer out and death), and length of follow up period.

\section{Measurement of outcomes}

Reported rates of retention in care, loss to follow-up, death and transfer out were collected from included studies. The rate of retention in care was defined as the rate of persons in the study who remain in care across periods of follow-up which was no missed visit of clinical schedule for more than three consecutive months. Study attrition was defined as the number of patients who were lost to follow-up, transferred out, or died [16]. While LTFU was defined as HIV positive patients who miss scheduled visits to the clinic for more than three consecutive months after the last visit [17]. Death and transfer out were defined as confirmed in the patient's record by the clinicians who were in charge of care [18].
In order to facilitate analysis, all rates were changed into100 person years of observation.

Where available, statistically significant measures of association were collected for factors associated with retention in care or attrition from care identified by studies included in the study. Then pooled odds ratio was calculated using frequency values from the primary studies and identified factors were classified as being either socio-demographic or clinical factors associated with patient retention or attrition.

\section{Heterogeneity and publication bias}

Study heterogeneity was assessed by calculating $I^{2}$ test statistics. Statistical significance was set at $p<0.05 I^{2}$ scores were classified into low, moderate and high inconsistency based on the $\mathrm{I}^{2}$ value of less than 25,50 and $75 \%$ respectively [19]. Random effect analysis was carried out to determine the pooled estimates of patient retention and attrition. Publication bias was assessed using Egger's test. For meta-analysis result with statistically significant publication bias, the Duval and Tweedie nonparametric trim and fill analysis using the random effect method of analysis was conducted [20].

\section{Statistical methods and analysis}

Data analysis was conducted using Stata version 14 . Pooled prevalence of LTFU, death and transfer out were estimated using each study prevalence and standard error with 95\% confidence interval (CI). For LTFU, we used both pooled prevalence and incidence density separately since most of the primary studies were follow up studies. Separate meta-analysis was conducted for the LTFU, death and transfer out outcomes. The result of meta-analysis was presented using forest plots. The meta-analysis was conducted using the random effects model of analysis since it minimizes heterogeneity of the included studies [21]. Subgroup analysis was conducted for the incidence rate of loss to follow up. Studies were stratified into subgroups based on length of follow up,

\section{Results}

A total of 3910 records were identified through online database. Of these, 1820 were identified through PubMed 900 were identified through Google Scholar, 980 were identified through Google Search and 200 from AJOL. An additional 2 articles were identified through unpublished sources. A total of 3912 were screened for inclusion. One hundred twenty were found to be duplicates and removed. Three thousands seven hundred ninety two were screened for inclusion and 3717 were excluded by title and abstract review. The full text of 75 articles were assessed for eligibility. Of these, only 45 articles passed the minimum quality score of 5 out of 9 
points and were included in the meta-analysis. A quality appraisal table can be found in (Additional file 1).

\section{Characteristics of included studies}

Most (32) of the designs of the primary articles was retrospective follow up $[9,10,16-18,22-48]$, five case control [8, 49-52], six prospective cohort study [37, 53-58] and two cross sectional survey designs $[59,60]$. Every region of Ethiopia was represented in the included studies. A total of 546,250 study participants were included from 45 articles Fig. 1. Moreover, study characteristics can be found in Table 1 .

\section{Magnitude of retention in HIV care}

Of the 45 original articles, 32 articles reported magnitude of patient retention in HIV care in Ethiopia [8-10, 17, 23-28, 30-32, 34, 36, 37, 41-45, 48, 52-58, 60, 62, 63]. The magnitude of retention in HIV care was $70.65 \%$ (95\% CI, 68.19, 73.11) with $\mathrm{I}^{2}$ value of $99.9 \%$ at $P$-value $<0.001$. The minimum retention was $32.50 \%$ (95\% CI, 28.56 to 36.44) in a 9 years follow up period [24] and the maximum retention was $94 \%$ (95\% CI, 90.1 to 97.7 ) in 1 year. The result is given in Fig. 2 .

The maximum and minimum follow up period was 14 years and 3 months respectively. Except one article that used 3 months of follow up [27], all original studies used a follow up period of above 1 year. Most (19) of the studies that reported a follow up period from 2 to 5 years had average retention in care of $71.09 \%$ (95\% CI, $68.75,73.44)$. Furthermore, 9 articles that used more than 5 years follow up period that reported on average retention rate of $68.92 \%$ (95\% CI, 65.02, and 72.81) Fig. 3.

The magnitude of attrition was an aggregations of LTFU, transfer out and death. Accordingly, the magnitude of loss to follow up was $15.17 \%$ (95\% CI: 11.86 , 18.47). The lowest and highest rate of loss to follow up was $3.13 \%$ (95\% CI: $2.90,3.36)$ and $31.40 \%$ (95\% CI: 31.37, 31.43) Fig. 4.

\section{Magnitude of attrition rate of HIV/AIDS patients in Ethiopia}

Incidence of loss to follow up was $13.79 / 100$ person years of observation (95\% CI, 9.66-17.93). The incidence rate was highest in the follow up years 2 through 5 years which was $16.69 / 100$ person years of observation, (95\% CI, 6.77-26.61). Subgroup analysis of incidence rate of loss to follow up was reported by 12 papers with resulted cumulative incidence density of $13.79 / 100$ person years of observation (95\% CI, 9.66-17.93). It is higher in the follow up years ranged from 2 to 5 years $16.69 / 100$ person years of observation, (95\% CI, 6.77-26.61) Fig. 5.

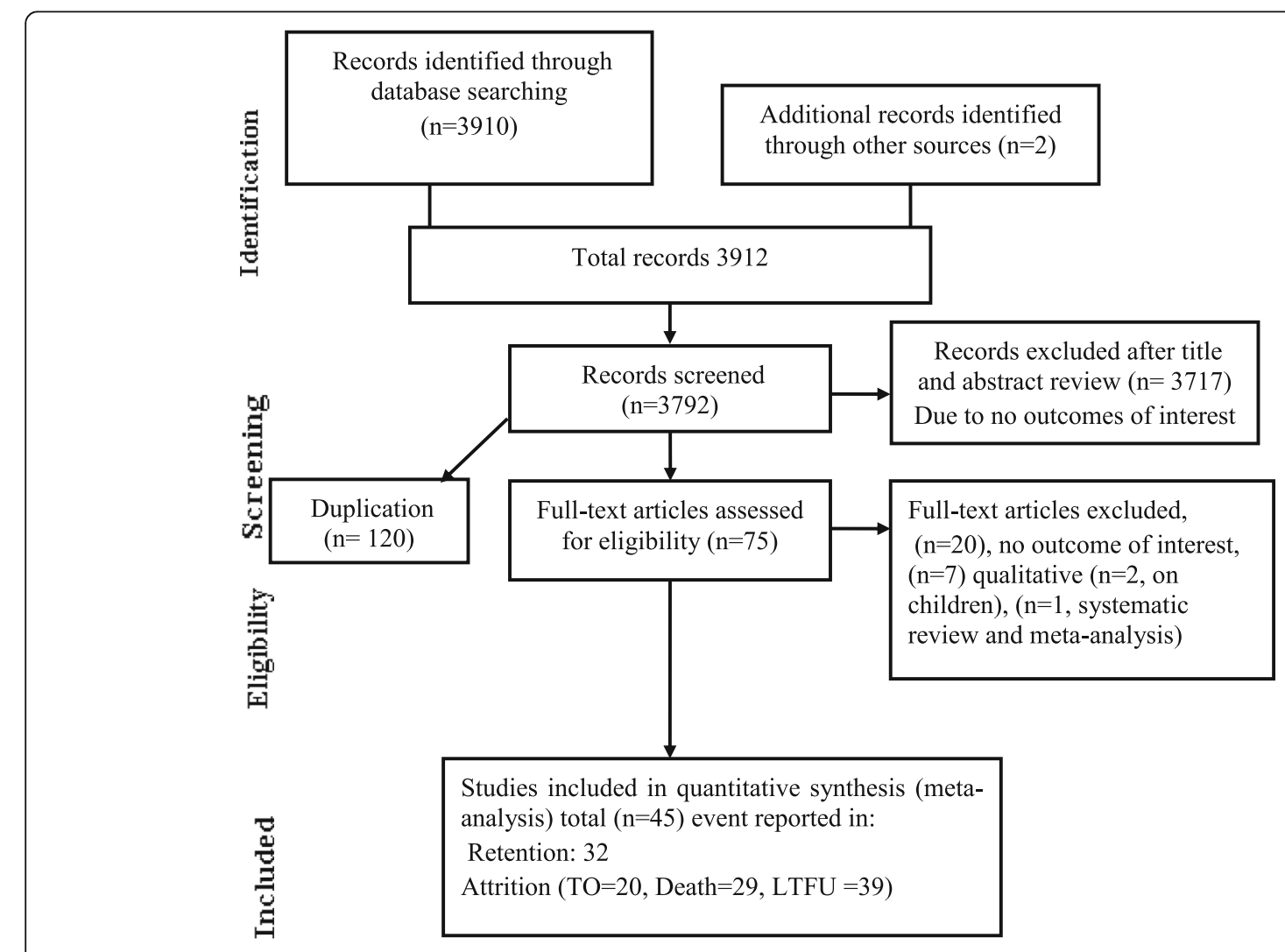

Fig. 1 Studies included in systematic review and meta-analysis of HIV patients attrition and its determinants in Ethiopia 
Table 1 Characteristics of included articles $(n=45)$

\begin{tabular}{lllll}
\hline Authors and year & (n) & Study design & Study area & Major objectives of the study \\
\hline Takele et al. [24] & 542 & $\begin{array}{l}\text { Retrospective } \\
\text { cohort }\end{array}$ & $\begin{array}{l}\text { Bichena Health center, } \\
\text { Northwest, Ethiopia }\end{array}$ & $\begin{array}{l}\text { To assess the time to lost follow } \\
\text { up and its predictors among } \\
\text { adult HIV positive people } \\
\text { receiving ART }\end{array}$
\end{tabular}

Yigzaw et al. [22] $484 \quad$ Retrospective Debre Markos referral cohort hospital, Northwest, Ethiopia
To determine the incidence and predictors of loss to follow up among HIV positive adults on ART
Karamara general hospital, Jigjiga town Eastern Ethiopia
To measure incidence and predictors of loss to follow up among adult ART clients.
Berheto et al. [23] 8009 Retrospective cohort
Four health centers and 2 To examine the effects of mental hospitals in Southern, Ethiopia health training on HIV patient retention in care.
Assemie et al. [17] 602 Retrospective cohort
Pawi General Hospital, northwest Ethiopia
To assess incidence of lost-tofollow-up and its predictors among HIV-positive adults after initiation of ART
Major findings

Prevalence of lost to follow up was $40.8 \%$ and incidence was 13.45/100 person years. Predictors of loss to follow up were:

$>$ Poor drug adherence AHR, 2.91 (2.08-4.09),

$>$ TDF based base line regimen AHR, 1.63 (1.20-2.20),

$>$ baseline regimen change AHR $1.79(1.08-2.97)$

$>$ Poor functional status AHR, 2.71 (2.01-3.66)

About $17.36 \%$ of the individual were lost from ART follow-up. Rate of lost to follow-up was found to be 3.7 per 100 person- year's observation and $30.95 \%$ occurred within the last years of follow up. The predictors for LTFU were:

$>$ ART Regimen [(AZT-3TC-NVP, AHR $(95 \% \mathrm{Cl}=2.79(1.07,7.23))$,

$\gg$ AZT-3TC-EFV, AHR $(95 \% \mathrm{Cl})=3.14$ $(1.13,8.08)$

$\gg$ TDF-3TC-EFV, AHR $(95 \% \mathrm{Cl}=9.3$ $(3.75,23.8)]$,

$>$ good ART adherence [AHR $(95 \% \mathrm{Cl})=0.54(0.3,0.9)]$

$>$ WHO clinical stage IV [AHR: $95 \% \mathrm{Cl}=2.75(1.23-6.16)]$,

$>$ Urban residence $[$ AHR: $95 \% \mathrm{Cl})=$ 0.6 (0.37-0.99),

$>$ no cell phone $[$ AHR: $95 \% \mathrm{Cl})=1.9$ (1.14-3.4)]

$>$ Age categories [ $[35-44$ years $(\mathrm{AHR}(95 \% \mathrm{Cl})=0.32(0.15-0.67)$

$>45+$ years $($ AHR $(95 \% \mathrm{Cl})=0.33$ (0.13-0.83)].

The incidence rate of loss to follow up in the cohort was $26.6 \%(95 \% \mathrm{Cl}$; 18.1-29.6) per 100 person months. Factors associated with LTFU were;

$>$ Patients with male sex [HR: $2.1 \mathrm{Cl}$, (1.3-3.4)]

$>$ patients whose next appointment weren't recorded [HR: $1.2,95 \% \mathrm{Cl}$; (1.12-1.36)]

$>$ patients who did not disclose their status to any one [HR: 2.8, 95\% Cl; (2.22-5.23)]

The incidence of attrition was 6.5 per 100 person-years

$>21 \%$ higher in the unexposed group (HR 1.21; 95\% Cl 1.1, 1.3)

$>$ Retention in care was significantly higher in the mental health trained group. Independent risk factors for attrition were;

$>$ WHO clinical staging III/IV

$\gg$ Tuberculosis co-infection

$>$ the male gender

$>$ Poor functional status

Cumulative incidence of lost-tofollow-up after ART initiation was high, 11.6 (95\% Cl 9.8-13.7) per 100 adult-years follow-up time. Independent significant predictors of lost to follow up were;

$>$ Being aged $15-28$ years $(\mathrm{AHR}=$ $0.44 ; 95 \%$ Cl 0.24-0.83)

$>$ being on WHO clinical stage IV (AHR $=2.09 ; 95 \% \mathrm{Cl} 1.02-3.13$ )

$\triangle$ Receiving isoniazid preventive therapy (AHR $=0.11 ; 95 \% \mathrm{Cl} 0.06$ 0.18). 
Table 1 Characteristics of included articles $(n=45)$ (Continued)

\begin{tabular}{|c|c|c|c|c|c|}
\hline Authors and year & (n) & Study design & Study area & Major objectives of the study & Major findings \\
\hline Adewo et al. [25] & 652 & $\begin{array}{l}\text { Retrospective } \\
\text { cohort }\end{array}$ & $\begin{array}{l}\text { Tepi General Hospital in } \\
\text { South West Ethiopia. }\end{array}$ & $\begin{array}{l}\text { to assess factors related } \\
\text { with time to attrition }\end{array}$ & $\begin{array}{l}179 \text { patients were lost to follow up } \\
\text { and } 37 \text { patients died, contributing to } \\
\text { an overall attrition of } 33.13 \% \text {. During } \\
\text { the early six months the attrition rate } \\
\text { was } 89.8 \% \text {. } \\
>\text { Not starting cotrimoxazole } \\
\text { prophylaxis (AHR }=1.51,95 \% \mathrm{Cl} \text {, } \\
1.02-2.25 \text { ) } \\
>\text { being co-infected with } \\
\text { tuberculosis (TB) (AHR }=2.16 \text {, } \\
95 \% \mathrm{Cl}, 1.35-3.45 \text { ) } \\
>\text { living further than } 10 \mathrm{~km} \text { away } \\
\text { from the hospital (AHR }=1.44 \text {, } \\
95 \% \mathrm{Cl}, 1.07-2.0 \text { ) } \\
>\text { Not disclosed status of HIV } \\
\text { (AHR = 3.04) were factors } \\
\text { significantly associated with } \\
\text { time to attrition. }\end{array}$ \\
\hline Gesesew et al. [26] & 3607 & $\begin{array}{l}\text { Retrospective } \\
\text { cohort }\end{array}$ & $\begin{array}{l}\text { Jimma University } \\
\text { Teaching Hospital, } \\
\text { Western Ethiopia }\end{array}$ & $\begin{array}{l}\text { to assess prevalence, trend } \\
\text { and risk factors for ART } \\
\text { discontinuation }\end{array}$ & $\begin{array}{l}1090(22.3 \%) \text { had discontinued, } 954 \\
(19.5 \%) \text { had transferred out, } 300 \\
(6.1 \%) \text { had died, } 2517 \text { ( } 51.4 \%) \text { were } \\
\text { alive and on ART. The trend of ART } \\
\text { discontinuation showed an upward } \\
\text { direction in the recent times and } \\
\text { reached a peak, accounting for a } \\
\text { magnitude of } 10 \% \text {, in } 2004 \text { and } \\
2005 \text {. } \\
>\text { Being a female (AOR }=2.1,95 \% \mathrm{Cl} \text { : } \\
1.7-2.8) \text {, } \\
>\text { Having an immunological failure } \\
\text { (AOR }=2.3,1.9-8.2) \\
>\text { having tuberculosis/HIV co- } \\
\text { infection (AOR = 1.5, 1.1-2.1) } \\
>\text { No previous history of HIV testing } \\
\text { (AOR = 1.8, 1.4-2.9) were the risk } \\
\text { factors for ART discontinuation. }\end{array}$ \\
\hline
\end{tabular}

\begin{tabular}{|c|c|c|c|c|}
\hline $\begin{array}{l}\text { Bucciardini } \\
\text { et al. [53] }\end{array}$ & 1198 & $\begin{array}{l}\text { prospective } \\
\text { cohort }\end{array}$ & $\begin{array}{l}\text { In seven health facilities } \\
\text { in Tigray in northern } \\
\text { Ethiopia. }\end{array}$ & $\begin{array}{l}\text { To determine predictors of } \\
\text { patient attrition after } 12 \\
\text { months in care }\end{array}$ \\
\hline
\end{tabular}

$\begin{array}{llll}\begin{array}{l}\text { Wilhelmson } \\ \text { et al. [27] }\end{array} & 383 & \begin{array}{l}\text { retrospective } \\ \text { cohort }\end{array} & \begin{array}{l}\text { Adama Hospital, central } \\ \text { Ethiopia }\end{array}\end{array} \quad \begin{aligned} & \begin{array}{l}\text { To determine retention in } \\ \text { care among patients receiving } \\ \text { second-line ART in a public } \\ \text { hospital }\end{array}\end{aligned}$

Tiruneh et al. [10] 222 retrospective Addis Ababa, Central cohort Ethiopia

months in care
Kaplan-Meier estimates of retention in care were $83.9,82.1$ and $79.8 \%$ at 12,18 and 24 months after starting ART, respectively. Attrition was mainly due to loss to follow-up (6.8\%), transferred-out patients (9.5\%) and mortality (4.4\%). Factors associated with attrition were; $>$ Male sex

$>$ CD4 count $<200$ cells $/ \mu \mathrm{L}$

$>$ Type of health facility

At the end of study follow-up, $80.5 \%$ of patients remained in care (adults and adolescents $79.8 \%$; children 85.7\%). LTFU among adults and adolescents was associated with;

$>$ baseline CD4 cell count 100 cells/ $\mathrm{mm} 3$ and

$>$ First-line regimen failure that was not confirmed by HIV RNA testing.

Thirty percent were LTFU by end of the study; the median time to LTFU was 1675 days. Higher risk of LTFU was associated with:

$>$ Baseline CD4 counts $<100$ and $>$ 200 cells/uL $(H R=1.62 ; 95 \% \mathrm{Cl}$ : 1.03-2.55; and $\mathrm{HR}=2.06$; $95 \% \mathrm{Cl}$ : $1.15-3.70$, compared with patients with baselineCD4 counts of 100200 cells/uL.

$>$ Bedridden at baseline $(H R=2.05$; 95\%Cls [1.11-3.80])

$>$ Those with no or only primary education ( $\mathrm{HR}=1.50 ; 95 \% \mathrm{Cls}$ [1.00-2.24]) were more likely to be LTFU.

$>$ The qualitative data revealed that 
Table 1 Characteristics of included articles $(n=45)$ (Continued)

\begin{tabular}{lllll}
\hline Authors and year & (n) & Study design & Study area & Major objectives of the study \\
\hline Megerso et al. [49] & 1248 & Case control & $\begin{array}{l}\text { Oromia, central and } \\
\text { western Ethiopia }\end{array}$ & $\begin{array}{l}\text { identifying correlates of loss to } \\
\text { follow-up in ART among adult } \\
\text { patients }\end{array}$
\end{tabular}
$\begin{array}{lll}\text { Mitiku et al. [28] } 346 \quad \begin{array}{l}\text { retrospective } \\ \text { cohort }\end{array} & \begin{array}{l}\text { South and North Wollo, } \\ \text { Oromia special zone, }\end{array}\end{array}$
To determine levels and determinants of LFU under Option B+ among pregnant and breastfeeding women compared death and loss to follow-up (LTFU) rates among ART patients among patients in hospitals and health centers
Dessalegn

et al. [50]
$727 \quad$ Case control
Wukro primary public hospital, Northern Ethiopia to assess the magnitude and predictors of loss to follow-up among adult ART clients
Major findings

fear of stigma, care dissatisfaction, use of holy water, and economic constraints discouraged retention in care.

factors which increased the risk of loss to follow-up in ART were;

$>$ Age 15-24 years [AOR], 19.82 95\% Cl: $6.80,57.73)$;

$>$ day laborers (AOR, 5.36; $95 \%[\mathrm{Cl}]$ : $3.23,8.89)$,

$>$ rural residents (AOR, 2.35; 95\% Cl: $1.45,3.89)$,

$\triangleright$ WHO clinical stage IV (AOR, 2.29: $95 \%$ Cl: $1.45,3.62)$,

$>$ Baseline CD4,350 cells/mL (AOR, 2.06; $95 \% \mathrm{Cl}: 1.36,3.13)$,

$>$ suboptimal adherence of ART (AOR, 7.42; 95\% Cl: 1.87, 29.41)

Overall, 57 (16.5\%) women were LTFU. The cumulative proportions of LTFU at 6, 12 and 24 months were $11.9,15.7$ and $22.6 \%$, respectively.

$>$ The risk of LTFU was higher in younger women 18 to 24 years than 30 to 40 years: (AHR $=2.3$; $95 \%$ (Cl): 1.2 to 4.5 )

$>$ In those attending hospitals compared to those attending health centers (AHR: 1.8; 95\% Cl: 1.1 to 3.2$)$,

$>$ In patients starting ART on the same day of diagnosis (AHR: 1.85; 95\% Cl: 1.1 to 3.2 )

$>$ Missing CD4 cell counts at ART initiation (AHR: 2.3; 95\% Cl: 1.2 to 4.4).

24.6\% were either dead or LTFU, resulting in a retention rate of $75.4 \%$. The death rates were 3.0 and 1.5 and the LTFU rate were 9.0 and 10.9 per 100 person-years of observation in health centers and hospitals, respectively. The competing-risk regression model showed that;

$\triangleright$ The longer gap between testing and initiation of ART,

$>$ body mass index $\geq 18.5$ (AHR, $0.58(95 \% \mathrm{Cl}, 0.38-0.91)$

$\triangleright$ advanced WHO clinical stage

$>$ No Isoniazid prophylaxis (AHR

$1.90(95 \% \mathrm{Cl}, 1.10-3.23)$

$>$ Age 26-39 (AHR, $0.59(95 \% \mathrm{Cl}$, $0.42-0.83)$

$>$ Secondary and above educational compared to no education status (AHR, 0.58 (95\% Cl, 0.39-0.67) were independently associated with LTFU.

$>$ Moreover, baseline tuberculosis disease, poor functional status /bed ridden (AHR, $5.35(95 \% \mathrm{Cl}$, 1.67-17.1), and follow-up at a health center were associated with an elevated probability of death.

$11 \%$ of them were loss to follow up. Factors associated with LTF were:

$>$ Absence of bereavement concern AOR, $0.12(0.046,0.30)$

$>$ not provided Isoniazide (INH) prophylaxis AOR, 3.04 (1.3, 7.3)

$\triangleright$ The presence of side effects AOR, $12.34(4.86,31.35)$

$>$ Earlier ( $<36$ month) periods after 
Table 1 Characteristics of included articles $(n=45)$ (Continued)

\begin{tabular}{|c|c|c|c|c|}
\hline Authors and year & (n) & Study design & Study area & Major objectives of the study \\
\hline Melaku et al. [30] & 93,418 & $\begin{array}{l}\text { retrospective } \\
\text { cohort }\end{array}$ & Nation wide & $\begin{array}{l}\text { To measure trend and treatment } \\
\text { outcomes of HIV treatment }\end{array}$ \\
\hline
\end{tabular}

Mekuria et al. [31] 836 retrospective Addis Ababa, Central cohort Ethiopia
Bucciardini et al. [55]

Assefa et al. [32]
11,371 retrospective cohort three health facilities in Addis Ababa, Central Ethiopia
To describe the proportion of patients who are retained in HIV care and characterize predictors of attrition among HIV-infected adults receiving CART care and its associated determinants
To identify the level of long-term outcomes and their determinants in patients on ART in Ethiopia
Major finding

ART AOR, $23.54(8.87,62.45)$

$24 \%$ of patients were LTF before ART initiation. Among those initiating

ART, attrition was 30\% after 36

months, with most occurring within the first 6 months. Recorded death after ART initiation was 6.4 and $9.2 \%$ at 6 and 36 months, respectively, and decreased over time. Younger age, male gender, never being married, no formal education, low CD4+ cell count, and advanced WHO stage were associated with increased LTFU. Death was lower among younger adults, females, married individuals, those with higher CD4+ cell counts and lower WHO stage at ART initiation

A total of 178 (28.4\%) pre-ART patients were lost to Follow up, 93\% of which occurred within the first six months. The independent predictors included:

$>$ Not having been started on cotrimoxazole prophylaxis $[\mathrm{AHR}]=1.77,95 \%,[\mathrm{Cl}], 1.12-2.79$ ),

$>$ baseline CD4 count of or above 350 cells $/ \mathrm{mm} 3$ (AHR $=1.87$, $95 \% \mathrm{Cl}, 1.02-3.45)$

$>$ An undisclosed HIV status (AHR = $3.04,95 \% \mathrm{Cl}, 2.07-4.45$ ).

Nearly $80 \%(95 \% \mathrm{Cl}: 76.7,82.1)$ of the patients were retained in care in the first 3 and half years of antiretroviral therapy. After successfully tracing more than half of the LTFU patients, the updated one year retention in care estimate became $86 \%$ (95\% Cl: $83.41,88.17 \%)$.

$>$ Severe immune deficiency at enrolment in care/or at ART initiation

$\gg$ 'bed-ridden' or 'ambulatory' functional status at the start of ART predicted attrition.

Overall $85.1 \%$ of their patients retained after one year from starting ART. Loss to follow-up (5.5\%) and transfers to other health facilities (6.6) were the main determinant of attrition. The factors associated with retention were;

$\gg$ The type of health facilities,

$>$ Active TB (HR 1.72, 95\% Cl: 1.23-2.41)

$\gg$ Male gender (AHR, $1.34(955 \mathrm{Cl}$ 1.04 to 1.7$) 4$

Retention rates were 82,74 , and $72 \%$ at 24,60 , and 84 months on ART, respectively. Retention was associated with:

$>$ Male sex, adolescent age, marital status, advanced HIV disease, Illiteracy and peer-support services

$>$ However, long-term retention was associated independently with:

$\triangleright$ only male sex (AHR) 0.68 (0.56 to 0.77)]

$>$ married patients [with AHR 0.62 (0.54 to 0.72$)$ ]

$\triangleright$ peer-support services [with AHR 1.62 (1.58 to 1.66$)]$ 
Table 1 Characteristics of included articles ( $n=45)$ (Continued)

\begin{tabular}{|c|c|c|c|c|c|}
\hline Authors and year & $(n)$ & Study design & Study area & Major objectives of the study & Major findings \\
\hline Berheto et al. [61] & 2133 & $\begin{array}{l}\text { retrospective } \\
\text { cohort }\end{array}$ & $\begin{array}{l}\text { Mizan-Aman General } \\
\text { Hospital in the Southern } \\
\text { Ethiopia }\end{array}$ & $\begin{array}{l}\text { aimed at determining the } \\
\text { incidence and risk factors for } \\
\text { LTFU in HIV patients on ART }\end{array}$ & 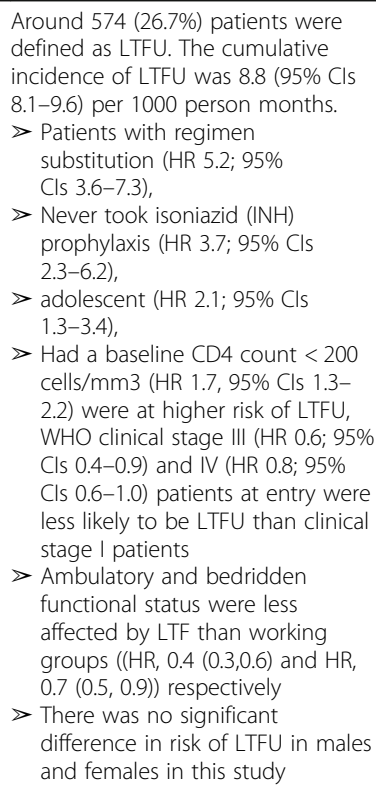 \\
\hline
\end{tabular}

Reepalu et al. [34] 678 Prospective Five health centers in compared virological suppression cohort Adama, Central Ethiopia

(VS) rates, mortality, and

retention in care in HIV-positive adults receiving care

To determine loss to follow up

and its determinants cohort

3012 Cross sectional Gondar, Northwest

Wubshet

et al. [59]
Ethiopia
To determine the outcome and factors associated with LTF among HIV patients
No difference in retention in care between TB and non-TB patients was observed during follow-up; 25 (3.7\%) patients died, and 17 (2.5\%) were lost to follow-up $(P=.30$ and $P=.83$, respectively).

51 (9.8\%) were loss giving a LTFU rate of 8.2 per 100 person- years. From these LTFU, 21 (41\%) occurred within the first Six months of ART initiation. The independent predictors of LTFU of patient were: $\triangleright$ being smear positive pulmonary TB $[$ AHR $(95 \% \mathrm{Cl})=(2.05$ $(1.02,4.12)]$,

$>$ male gender $[$ AHR $(95 \% \mathrm{Cl})=(2.73$

$$
(1.31,5.66)] \text {, }
$$

$>$ regiment AZT-3TC-NVP [AHR $(95 \% \mathrm{Cl})=(3.47(1.02,11.83)]$ and

$>$ Weight $\geq 60 \mathrm{~kg}[$ AHR $(95 \%$ $\mathrm{Cl})=(3.47(1.02,11.83)]$

Out of the 551 patients LTF, 486 (88.20\%) were successfully tracked. Death was the most common reason accounted for 233 (47.94\%) of the lost to follow-up. Reasons for non-deaths losses include: stopped antiretroviral treatment due to different reasons, 135 (53.36\%), and relocation to another antiretroviral treatment program by self- transfer, $118(46.64 \%)$. The rate of mortality in the first six months was 72.12 per 100 person-years $(95 \% \mathrm{Cl}: 61.80$ 84.24) but this sharply decreased after 12 months to 7.92 per 100 person-years (95\% Cl: 4.44-14.41). Baseline clinical characteristics were strongly associated with outcome such as presence of tuberculosis infection at ART initiation, functional status (both ambulatory and bed ridden); CD4 cell count, 100 cells $/ \mathrm{mL}$, and WHO stage III and IV were strongly associated with mortality. On the other hand, male sex, bedridden functional status and 
Table 1 Characteristics of included articles $(n=45)$ (Continued)

\begin{tabular}{lllll}
\hline Authors and year & $(\mathrm{n})$ & Study design & Study area & Major objectives of the study \\
\hline Asefa et al. [51] & 236 & Case control & $\begin{array}{l}\text { Nekemte Hospital, } \\
\text { western Ethiopia }\end{array}$ & $\begin{array}{l}\text { to assess determinants of } \\
\text { defaulting from antiretroviral } \\
\text { treatment }\end{array}$
\end{tabular}

Gondar, Northwest Ethiopia

Gondar, Northwest Ethiopia
To investigate factors associated with pre-ART LTFU in Ethiopia.
3012 Survey defaulting
treatment .

to evaluate mortality, loss to follow up, and retention in care cohort
Nationwide study
Intended to evaluate the outcomes of the ART services in 55 health facilities in Ethiopia.
Major findings

residence outside Gondar town were significantly associated with nondeath losses.

After controlling for possible confounders,

$>$ living far from the facility (out of the town) (AOR $=4.1 ; 95 \% \mathrm{Cl} 1.86$ to 9.42 ),

$>$ dependent patients for source of food $[A O R=13.9 ; 95 \% \mathrm{Cl} 4.23$ to 45.99],

$>$ patients with mental status not at ease $[\mathrm{AOR}=4.7 ; 95 \% \mathrm{Cl} 1.65$ to 13.35],

$>$ patients whose partners were HIV negative $[A O R=5.1 ; 95 \% \mathrm{Cl} 1.59$ to 16.63],

$>$ patients whose partners HIV status were unknown or not tested $[\mathrm{AOR}=2.8 ; 95 \% \mathrm{Cl} 1.23$ to 6.50]

$>$ Patients that fear stigma $[A O R=$ 8.3; $95 \% \mathrm{Cl} 2.88$ to 23.83 ] were statistically significant association.

factors were found to be independently associated with preART LTFU:

$\gg$ male gender $(\mathrm{AOR})=2.00(95 \% \mathrm{Cl}$ : $1.15,3.46)]$

$>$ higher baseline CD4 cell count (251-300 cells/ $\mu \mathrm{l}[\mathrm{AOR}=2.64$ (95\% Cl: $1.05,6.65)] ; 301-350$ cells/ $\mu \mathrm{l}[\mathrm{AOR}=5.21(95 \% \mathrm{Cl}: 1.94$ 13.99)], and $>350$ cells/ $\mu \mathrm{l}[\mathrm{AOR}=$ 12.10 (95\% Cl: 6.33, 23.12)] compared to CD4 cell count of $\leq 200$ cells/ $\mu \mathrm{l}$ )

$\triangleright$ Less advanced disease stage (WHO stage I $[\mathrm{AOR}=2.81(95 \% \mathrm{Cl}$ : $1.15,6.91)]$ compared to WHO stage IV).

$>$ Married patients [AOR $=0.39(95 \%$ Cl: $0.19,0.79)]$ had reduced odds of being LTFU.

$>$ Patients whose next visit date was not documented on their medical chart $[\mathrm{AOR}=241.39(95 \%$ Cl: 119.90, 485.97)]

$61.4 \%$ of the patients were retained on treatment, $10.4 \%$ died, and $31.4 \%$ were lost to follow up. Fifty-six percent of the deaths and $46 \%$ of those lost to follow up occurred in the first year of treatment.

$>$ Male gender (AHR) 3.26; 95\% Cl: 2.19-4.88)

$>$ CD4 count $\leq 200$ cells/ $\mu \mathrm{L}$ (AHR 5.02; 95\% Cl: 2.03-12.39),

$>$ tuberculosis (AHR 2.91; $95 \% \mathrm{Cl}$ : 2.11-4.02);

$>$ bed-ridden functional status (AHR 12.88; 95\% Cl: 8.19-20.26) were predictors of mortality,

$>$ Whereas only CD4 count $<200$ cells $/ \mu \mathrm{L}(\mathrm{HR}=1.33 ; 95 \% \mathrm{Cl}:(0.95$, 1.88 ) and ambulatory functional status ( $\mathrm{HR}=1.65 ; 95 \% \mathrm{Cl}$ : (1.22, 2.23) were significantly associated with LTF.

Health facilities were able to retain 29,893 (80\%), 20,079 (74\%) and 5069 $(68 \%)$ of their patients after 6,12 and 24 months on ART, respectively. Retention rates vary across health 
Table 1 Characteristics of included articles $(n=45)$ (Continued)

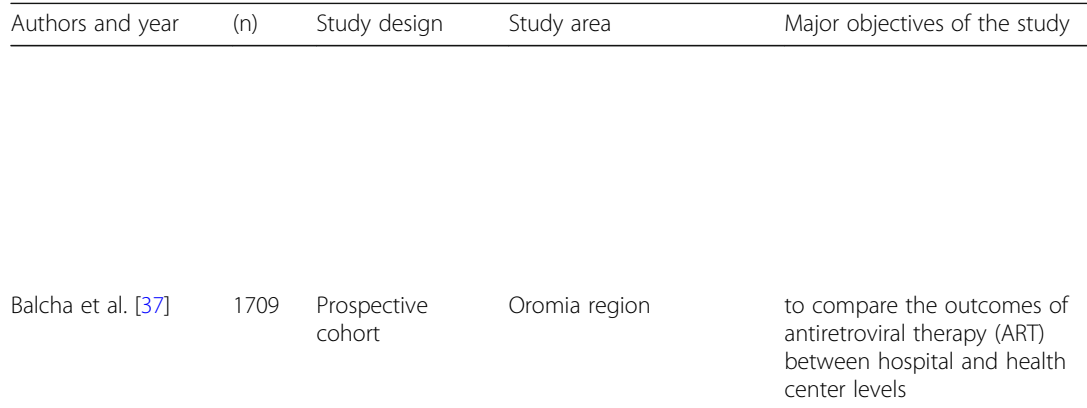

Deribe et al. [52] 1270 Case control Jimma University Teaching Hospital, western Ethiopia

Abebe et al., [18]

To determine Survival status of HIV positive adults on antiretroviral treatment
To determine the prevalence of and factors associated with defaulting from antiretroviral treatment (ART)
Major findings

facilities, ranging from 51 to $85 \%$ after 24 months on ART. Mortality was 5,6 and $8 \%$ after 6,12 and 24 months on ART. More than $79 \%$ of patients with available CD4-cell counts had a baseline CD4-cell counts less than 200 cells per micro-liter of blood.

1044 (61\%) remained alive and were on treatment after 24-month followup. In all, 835 (57\%) of ART patients at hospitals and 209 (83\%) at health centers were retained in the program. Of those who were alive and receiving ART, $79 \%$ of patients at health centers and $72 \%$ at hospitals were clinically or immunologically improving. In addition, 331 (23\%) patients at hospitals were LFTU as compared to $24(10 \%)$ of patients at health centers (relative risk [RR] at 95\% confidence interval [Cl]: 358 [.231-.555]). While $11 \%$ was the mortality rate at hospitals, $5 \%$ of patients at health centers also died (RR at 95\% Cl: .360 [.192-.673]).

Of 1270 patients who started ART 915 (72.0\%) were active ART users and 355 (28.0\%) had missed two or more clinical appointments. The latter comprised 173 (13.6\%) defaulters, 101 (8.0\%) who transferred out, 75 (5.9\%) who died, and $6(0.5 \%)$ who restarted ART. Reasons for defaulting were unclear in most cases. Reasons given were; loss of hope in medication, lack of food, Mental illness, holy water, no money for transport and other illnesses. Tracing was not successful because of incorrect address on the register in $61.6 \%$ of the cases. $\triangleright$ Taking hard drugs (cocaine, cannabis and IV drugs)

$>$ excessive alcohol consumption

$\gg$ Being bedridden,

$>$ living outside Jimma town

$>$ Having an HIV negative or unknown HIV status partner were associated with defaulting ART.

640 patient cards (379 alive and 261 death) adult HIV infected individuals were included in the study. General mean estimated survival time of patients after HAART initiation was improved.

Significant predictors of mortality after HAART initiation were: Lower baseline hemoglobin; Ambulatory and bed ridden functional status; Poor ART adherence; Advanced WHO clinical stage; Absence of recent TB prophylaxis; Unrecognized side effects; Persistent unexplained chronic diarrhea (>1 month)

40 transfer out to other health facilities

13 died

21 loss to follow up

258 did not develop TB

119 developed TB 
Table 1 Characteristics of included articles ( $n=45)$ (Continued)

\begin{tabular}{|c|c|c|c|c|}
\hline Authors and year & (n) & Study design & Study area & Major objectives of the study \\
\hline $\begin{array}{l}\text { Mekonnen } \\
\text { et al. [46] }\end{array}$ & 1533 & $\begin{array}{l}\text { Retrospective } \\
\text { cohort }\end{array}$ & $\begin{array}{l}\text { Jimma hospital southwest } \\
\text { Ethiopia }\end{array}$ & $\begin{array}{l}\text { to assess reasons and predicto } \\
\text { of regimen change from initial } \\
\text { highly active antiretroviral } \\
\text { therapy }\end{array}$ \\
\hline Chaka et al. [40] & 248 & $\begin{array}{l}\text { Retrospective } \\
\text { cohort }\end{array}$ & Adama, Central Ethiopia & $\begin{array}{l}\text { to assess Option B+ } \\
\text { PMTCT service intervention } \\
\text { outcomes. }\end{array}$ \\
\hline Tadege [41] & 1512 & $\begin{array}{l}\text { Retrospective } \\
\text { cohort }\end{array}$ & $\begin{array}{l}\text { Mettu Karl Hospital, } \\
\text { southwest Ethiopia }\end{array}$ & $\begin{array}{l}\text { to determine the major risk } \\
\text { factors of antiretroviral therapy } \\
\text { dropout }\end{array}$ \\
\hline
\end{tabular}

Gezea et al. [39] 305 Retrospective Mekelle, Northern cohort Ethiopia aimed at investigating the incidence and predictors of LTFU of TB/HIV co-infected patients

\section{Mekonnen et al. [38] 569 Retrospective Gondar, Northwest} cohort
Ethiopia to estimate the incidence of lost to follow up from ART care and identify the associated factors among HIV infected patients after first-line ART initiation

\begin{tabular}{|c|c|c|c|c|}
\hline $\begin{array}{l}\text { Damitew } \\
\text { et al. [44] }\end{array}$ & 784 & $\begin{array}{l}\text { Retrospective } \\
\text { cohort }\end{array}$ & $\begin{array}{l}\text { Kharamara hospital, } \\
\text { Somalia, Eastern Ethiopia }\end{array}$ & $\begin{array}{l}\text { to assess survival and identify } \\
\text { predictors of death in adult HIV- } \\
\text { infected patients initiating ART }\end{array}$ \\
\hline
\end{tabular}

Major findings

One in two (47.7\%) adults changed their antiretroviral therapy regimen. Patients who were above the primary level of education [Hazard ratio (HR) 1.241 (95\% Cl 1.070-1.440)] and with human immunodeficiency virus/Tuberculosis co-infection [HR 1.405 (95\% Cl 1.156-1.708)] had the higher risk of regimen change than their comparator.

Loss to follow-up from the Option $\mathrm{B}+$ continuum was 10 (4.2\%).

the risk of dropout for patients with primary education status was $10.58 \%$ greater as compared to illiterate $(p<0.0110)$. The probability of dropout for patients with marital status separated was about $16.82 \%$ higher than those patients with marital status divorced $(p<0.0070)$. Being merchant, farmer and daily labour had a greater risk of dropout as compared to a housewife.

45 of 305 (14.8\%) of TB/HIV coinfected adults were LTFU with an incidence rate of 4.5 new LTFUs per 100 Person Years (PYs) and a median follow up time of 3.1 years (Inter quartile Range (IQR): 0.8-5.3 Years). Hemoglobin level $\leq 11.0 \mathrm{~g} / \mathrm{dl}(\mathrm{AHR}=$ 2.660; 95\%Cl: 1.459-4.848), and any history of $\mathrm{Ol} / \mathrm{s}$ (AHR $=3.795 ; 95 \% \mathrm{Cl}$ : 1.165-12.364) were risk factors of LTFU. While, adverse drug events $(\mathrm{AHR}=0.451 ; 95 \% \mathrm{Cl}: 0.216-0.941)$, TB treatment completion $(A H R=0.121$; 95\% Cl: 0.057-0.254), and being on Isoniazid Preventive Therapy (IPT) $(\mathrm{AHR}=0.085 ;$ 95\%Cl: 0.012-0.628) had protective effect against LTFU.

The overall incidence rate of lost to follow up was 12.26 per 100 person years (95\% Cl (10.61-14.18)). Being underweight $(<18.5 \mathrm{~kg} / \mathrm{m} 2)$ (AHR, $1.52,95 \% \mathrm{Cl} 1.01-2.28)$, jobless (AHR, $2.22,95 \% \mathrm{Cl} 1.2-4.11)$, substance abuser (AHR, 1.84 95\% Cl 1.19-2.86), having sub-optimal adherence (fair/ poor) (AHR 6.33, 95\% Cl (3.90-10.26)), not receiving isoniazid prophylaxis (AHR 2.47, 95\% Cl (1.36-4.48)), ambulatory functional status (AHR $1.94,95 \%$ Cl (1.23-3.06)), having opportunistic infections (AHR, 1.74 95\% Cl 1.11-2.72), having CD4 count 201-349 cells/uL (AHR 0.58, 95\% Cl (0.38-0.88)) were found to be significant predictors of lost to follow up from ART service.

There were 87 (11.1\%) deaths yielding an overall mortality rate of 5.15/100 PYO (95\% Cl: 4.73-6.37). The estimated mortality was $8.4,9.8,11.3$, 12.7 and $14.1 \%$ at $6,12,24,36$ and 48 months respectively. The independent predictors of death were single marital status (AHR: 2.31; 95\%Cl: 1.18-4.50), a bedridden functional status (AHR: 5.91; 95\%Cl: 2.87-12.16), advanced WHO stage (AHR: 7.36; 95\%Cl: 3.17-17.12), BMI< 18.5 Kg/m2 (AHR: 2.20; 95\%Cl: 1.184.09), CD4 count $<50$ cells/ $\mu \mathrm{L}$ (AHR: 
Table 1 Characteristics of included articles $(n=45)$ (Continued)

\begin{tabular}{lllll}
\hline Authors and year & $(\mathrm{n})$ & Study design & Study area & Major objectives of the study \\
\hline Ayele et al. [43] & 730 & $\begin{array}{l}\text { Retrospective } \\
\text { cohort }\end{array}$ & $\begin{array}{l}\text { Kembata and Hadiya } \\
\text { zones }\end{array}$ & $\begin{array}{l}\text { To assesses treatment outcomes } \\
\text { and its determinants for HIV } \\
\text { patients on ART }\end{array}$
\end{tabular}

Bezabh et al. [57] 337 Retrospective Bahrdar and Gondar, cohort northwest Ethiopia

Awoke et al. [42] 2386 Retrospective cohort

Gondar, northwest Ethiopia

Mekuria et al. [48] cohort 870 Retrospe cohort

Addis Ababa, Central Ethiopia

Assefa et al. [9]

\author{
Major findings \\ 2.70; 95\%Cl: 1.26-5.80), severe \\ anemia (AHR: 4.57; 95\%Cl: 2.30-9.10), \\ and TB co-infection (AHR: 2.30; \\ 95\%Cl: 1.28-4.11) \\ A total of $92(12.6 \%)$ patients died, \\ 106 (14.5\%) were lost to follow-up, \\ and 109 (15\%) were transferred out. \\ Sixty three $(68 \%)$ deaths occurred in \\ the first 6 months of treatment. The \\ median survival time was 25 months \\ with IQR $[9,43]$. After adjustment for \\ confounders, WHO clinical stage IV \\ [HR 2.42; 95\% Cl, 1.19, 5.86], baseline \\ CD4 lymphocyte counts of 201 cell/ \\ $\mathrm{mm} 3$ and $350 \mathrm{cell} / \mathrm{mm} 3$ [HR 0.20; \\ 95\% Cl; 0.09-0.43], poor regimen \\ adherence [HR 2.70 95\% Cl: 1.4096 , \\ 5.20], baseline hemoglobin level of \\ $10 \mathrm{~g} / \mathrm{dl}$ and above [HR 0.23; $95 \% \mathrm{Cl}$ : \\ $0.14,0.37]$ and baseline functional \\ status of bedridden [HR 3.40; $95 \% \mathrm{Cl}$ : \\ $1.61,7.21]$ were associated with five \\ year survival of HIV patients on ART.
}

to determine patient, regimen, disease, patient-provider, and healthcare-related factors associated with adherence with ART

to determine and compare the long-term response of patients on nevirapine and efavirenz

To investigated virological suppression levels and its predictors of detectable viraemia

130 (75.6\%) had $\geq 95 \%$ adherence. In the multivariate analyses, a

higher baseline BMI (OR, 1.2; 95\% Cl $1.0,1.4)$ and use of reminder devices (OR, 9.1: $95 \% \mathrm{Cl} 2.0,41.6)$ remained positively associated with adherence

$70.58 \%$ were retain in clinical care

302 were transfer out to other health facilities

230 were lost to follow up

170 were dead

A total of 656 (75.4\%) patients, who were alive, were retained in HIV care. Virological suppression levels can be high in an established ART programme in a resource-limited setting

The ART program has been successful over several critical areas: (1) ART coverage improved from 4 to 54\%; (2) the median CD4 count/ $\mathrm{mm} 3$ at the time of ART initiation increased from 125 in 2005/ 6 to 231 in 2012/13; (3) retention in care after 12 months on ART has increased from 82 to $92 \%$. In spite of these successes, important challenges also remain: (1) ART coverage is not equitable: among regions (5.6-93\%), between children (25\%) and adults (60\%), and between female (54\%) and male patients (69\%); (2) retention in care is variable among regions (83-94\%); and, (3) the shift to second-line ART is slow and low (0.58\%).

Community health support workers (CHSWs) provided HIV and health education, counseling/social support, and facilitated communication with the HIV clinics. With 7 deaths and 3 transfers, the 12-month retention rate was $94 \%$ (95\% Cl 1/4 89-97\%), and no client was LTFU in the project. Between enrollment and 12 months, clients had significant $(P<.001)$ improvements in HIV knowledge $(17 \%$ increase), physical and mental quality of life (81 and 21\% increase), internalized 
Table 1 Characteristics of included articles $(n=45)$ (Continued)

\begin{tabular}{|c|c|c|c|c|c|}
\hline Authors and year & $(\mathrm{n})$ & Study design & Study area & Major objectives of the study & Major findings \\
\hline & & & & & $\begin{array}{l}\text { stigma ( } 97 \% \text { decrease), and perceived } \\
\text { social support ( } 24 \% \text { increase). }\end{array}$ \\
\hline Tadege [45] & 600 & $\begin{array}{l}\text { Retrospective } \\
\text { cohort }\end{array}$ & Illubabur & Time to death predictors & $\begin{array}{l}\text { The risk of death for patients who lived } \\
\text { with tuberculosis was about } 2.872 \text {-fold } \\
\text { times higher than those patients who } \\
\text { were negative. Most of the HIV/AIDS } \\
\text { patients on antiretroviral therapy were } \\
\text { died in a short period due to tuberculosis } \\
\text { comorbidity, began with lower amount of } \\
\text { CD4, being underweight, merchant, and } \\
\text { being on WHO clinical stage IV }\end{array}$ \\
\hline Telele et al. [58] & 874 & $\begin{array}{l}\text { Prospective } \\
\text { cohort }\end{array}$ & Nation wide & $\begin{array}{l}\text { To predict first-line ART outcome after } 6 \text { and } \\
12 \text { months }\end{array}$ & $\begin{array}{l}\text { The treatment failure rates were } 23.3 \text { and } \\
33.9 \% \text { at } 6 \text { and } 12 \text { months, respectively. } \\
\text { The odds of LTFU at month } 6 \text { increased } \\
\text { with baseline functional disabilities, WHO } \\
\text { stage III/VV, and CD4 cells }<50 / \mu l \text {. At } \\
\text { month } 6,131 / 874(15.0 \%) \text { patients were } \\
\text { dead }(n=62) \text { or LTFU due to other } \\
\text { reasons }(n=69) \text {. }\end{array}$ \\
\hline Assesfa et al. [12] & $\begin{array}{l}334, \\
819\end{array}$ & $\begin{array}{l}\text { Retrospective } \\
\text { cohort }\end{array}$ & Nation wide & $\begin{array}{l}\text { We aimed to analyze the ART } \\
\text { program in Ethiopia. }\end{array}$ & $\begin{array}{l}\text { While ART was being scaled up, retention } \\
\text { was recognized to be insufficient. To } \\
\text { improve retention, a second wave of } \\
\text { interventions, related to programmatic, } \\
\text { structural, socio-cultural, and patient infor } \\
\text { mation systems, have been implemented. } \\
\text { Retention rate increased from } \\
77 \% \text { in } 2004 / 5 \text { to } 92 \% \text { in } 2012 / 13 \text {. }\end{array}$ \\
\hline
\end{tabular}

Total number of participants 546,250

Key: AHR Adjusted Hazard Ratio, LTFU Loss to follow up

Most common contributing factors for patient attrition was loss to follow up (15.17\%), transfer out (12\%) and death $(5.71 \%)$ respectively Table 2.

\section{Mortality of HIV patients in Ethiopia}

Overall mortality of HIV patients in this meta-analysis was $6.75 \%$ (95\% CI: 6.22, 7.27). Mortality rates were lowest in the first years of follow up (4.4\% (95\% CI: 0.72, 8.16)) and highest when follow up exceeded 5 years (7.65\% (95\% CI: 6.38, 8.92)). Pooled mortality rates are shown in Fig. 6.

HIV patients transfer out from one to other health facility About 11.17\% (95\% CI: 7.12, 15.21) of all study subjects transferred out during the study period. The cumulative transfer out percentage was lowest in the earliest years of follow up, and highest by the end of the follow-up period. 5.18\% (95\% CI: 1.60, 8.76) and 18.35\% (95\% CI: 13.60, 23.11) Fig. 7.

\section{Factors related to patient retention and attrition Socio-demographic and behavioral factors}

Five original papers stated that marital status was associated with patient retention in clinical care. Of which three articles reported that married people were less likely to be lost to follow up $[8,30,51]$ and the probability of dropout for patients with separated marital status was about $16.82 \%$ higher than those patients with marital status divorced [41]. Another article [44] reported as single marital status as an independent predictor of death. Pooled odds ratio from 13 primary studies indicated that currently unmarried people are 1.52 times more likely not to be retained in clinical care (OR, 1.52, 95\% CI, 1.15-2.01). Moreover, ten papers reported that male patients were less likely to be retained in HIV care in Ethiopia [8, 16, 23, 30, 33, 36, 53, 55, 59, 60]. Yet, one study in Ethiopia reported that females were less likely to be retained in clinical care [26]. However, it was not statically significant from pooled analysis of odds ratio from18 primary studies (OR, 1.12, 95\% CI, 0.97-5.45). Similarly, eight papers $[17,22,23,28,30,36,49,54]$ reported that young age was an important predictor of loss to follow up but this was not statistically significant in the pooled analysis (OR, 0.88, 95\% CI, 0.27-2.89). Four papers reported that educational status had an influence on retention in care $[10,30,41,54]$. All except one [41] primary articles has reported that people with no or primary education were more likely to experience loss to follow up compared to those with secondary and above educational level. Two studies reported that urban residents were better in retention than their rural counterparts [22, 49]. Three papers indicated that economic constraints such as being dependent patients for source of food and daily laborers were risk factors for treatment interruption $[10,49,51]$. Being a merchant, farmer, daily labour and jobless had a greater risk of dropout [38, 41]. On the other hand, one study reported that merchants were at higher risk of death [45] However, except 


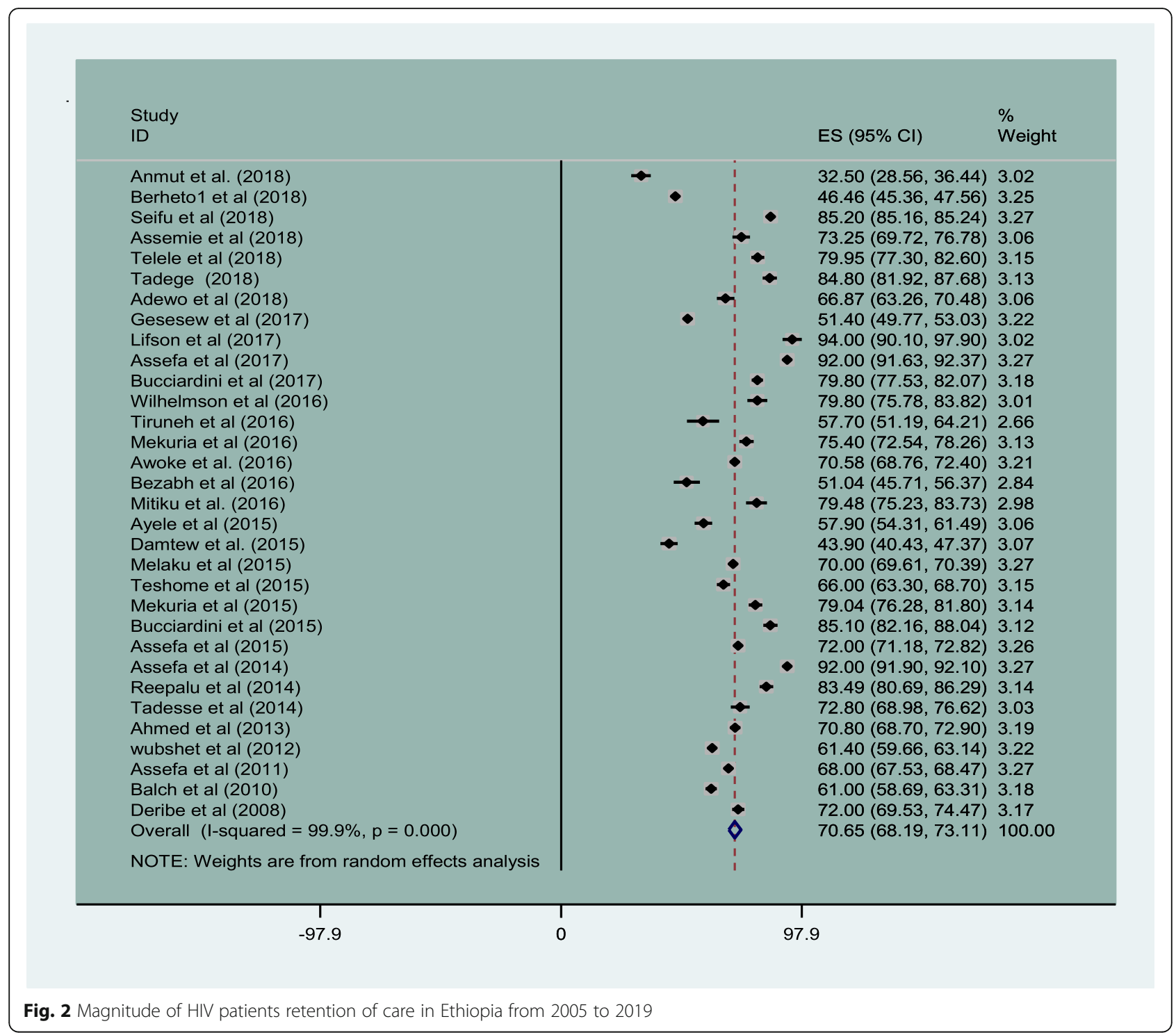

marital status, none of the socio-demographic factors were found statistically significant for patient retention in care (Table 3).

HIV patients who did not disclose their HIV status were 6.36 times more likely to experience attrition from clinical care (OR, 6.36, 95\% CI, 3.58-11.29). Patients who were not substance users were $59 \%$ more likely to be retained in clinical care (OR, 0.41, 95\% CI, 0.170.98). Mental health issues such as taking hard drugs (cocaine, cannabis and IV drugs) and excessive alcohol drinking were risk factors for treatment defaulting [52]. Any types of substance use was reported as risk for loss to follow up [38]. It was also reported that patients with higher score for stress were poor in ART adherence [57]. Moreover, patients with mental status being not at ease were at increased risk for loss to follow up [51] (Table 3).

\section{Clinical related factors}

Fourteen studies $[10,18,23,24,31,35,38,43,44,54,57-$ $60]$ indicated that poor functional status (ambulatory or bed ridden) was a factor for patient attrition (OR, 2.11, 95\% CI 1.33-3.34). Twelve papers [17, 18, 22, 23, 30, 43$45,49,54,58,59]$ reported that patients with advanced WHO clinical stages III or IV were also at greatest risk of death and loss to follow up (OR, 1.85, 95\% CI, 1.36-2.51). Seventeen papers $[8,10,27,29-31,35,38,43-45,49,55$, 57-60] reported that baseline CD4 count less than 200 cells/ $\mu \mathrm{L}$ and greater than 350 cells/ $\mu \mathrm{L}$ was reported as risk factor for attrition but it was not significant in the pooled odds ratio analysis (OR, 1.09, 95\% CI,0.49-2.41). Four papers reported that lower level of hemoglobin is a risk factor for death [18, 39, 43, 44]. Four studies reported that lower weight and BMI is risk factor for patient death and loss to follow up [38, 44, 45, 57]. 


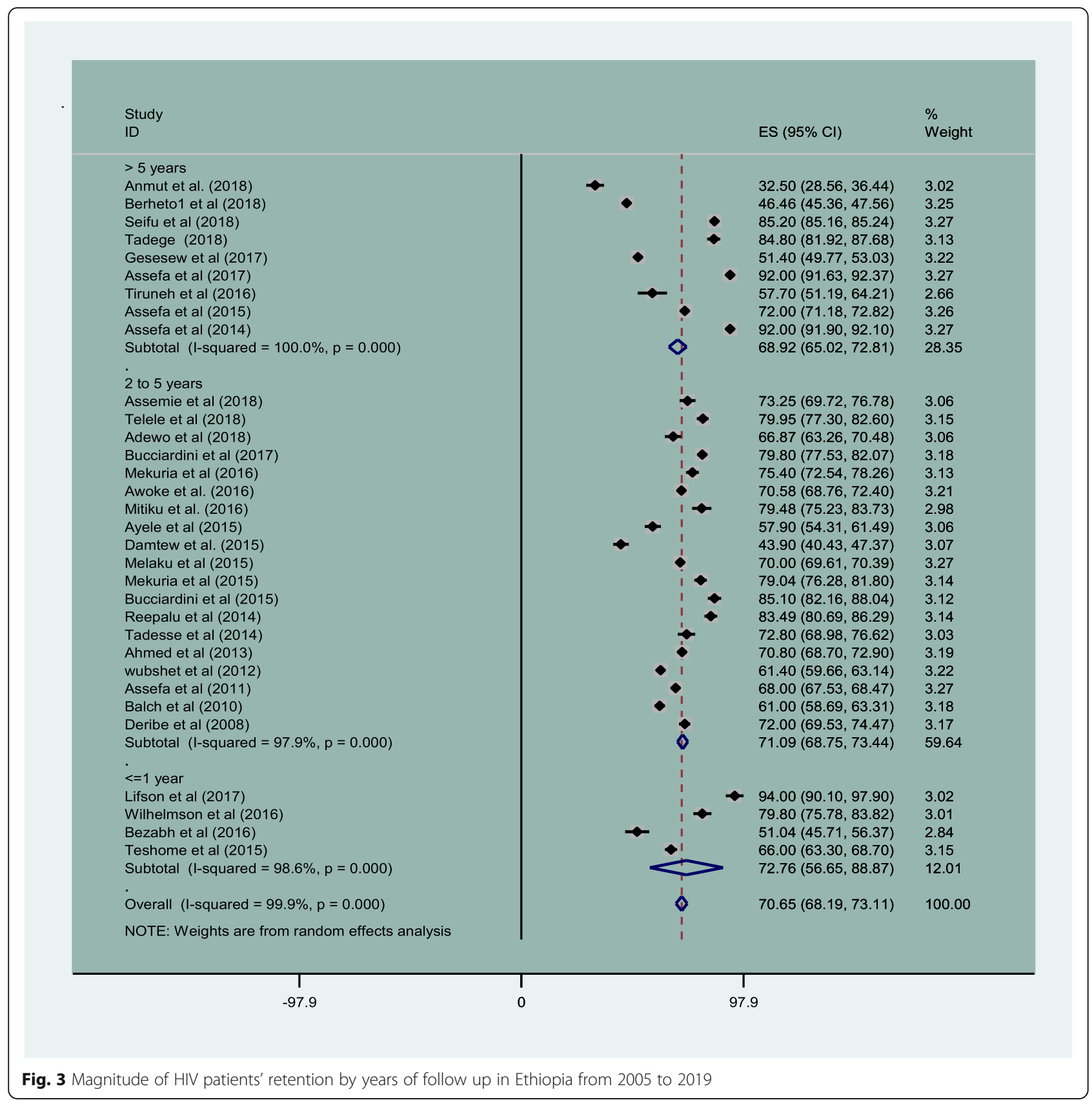

Treatment related factors such as baseline ART regimen of Zidovudine-Lamivudine-Nevirapine (AZT-3TCNVP) was key factor for patient attrition [22, 33]. Six studies [18, 22, 24, 38, 43, 57] demonstrated that poor drug adherence was a risk factor for patient attrition of both loss to follow up and death (OR, 6.60, 95\% CI 1.41-30.97). Three studies reported that adverse drug side effects are responsible for patient loss to follow up and death $[18,39,57]$. Six studies reported that opportunistic infection were the main responsible factors for patient death and loss to follow up includes [38, 39]. These included TB $[39,44-46]$ and diarrhea for more than 3 months led a risk of death [18]. Nine papers reported that provision of isoniazid preventive therapy (IPT) $[17,18,35,38,39,50,54]$ and CPT $[25,29]$ prophylaxis indicted that optimize patient retention.

Two papers reported on quality of care indicated that patients whose next appointment weren't recorded were at risk of loss to follow up $[8,16]$. Three papers reported that loss to follow up was higher among HIV patients in hospitals compared to health centers [28, 37, 54] while, one study reported that loss to follow up was higher among patients attending health centers than those in hospitals [53]. On the other hand, two studies reported 


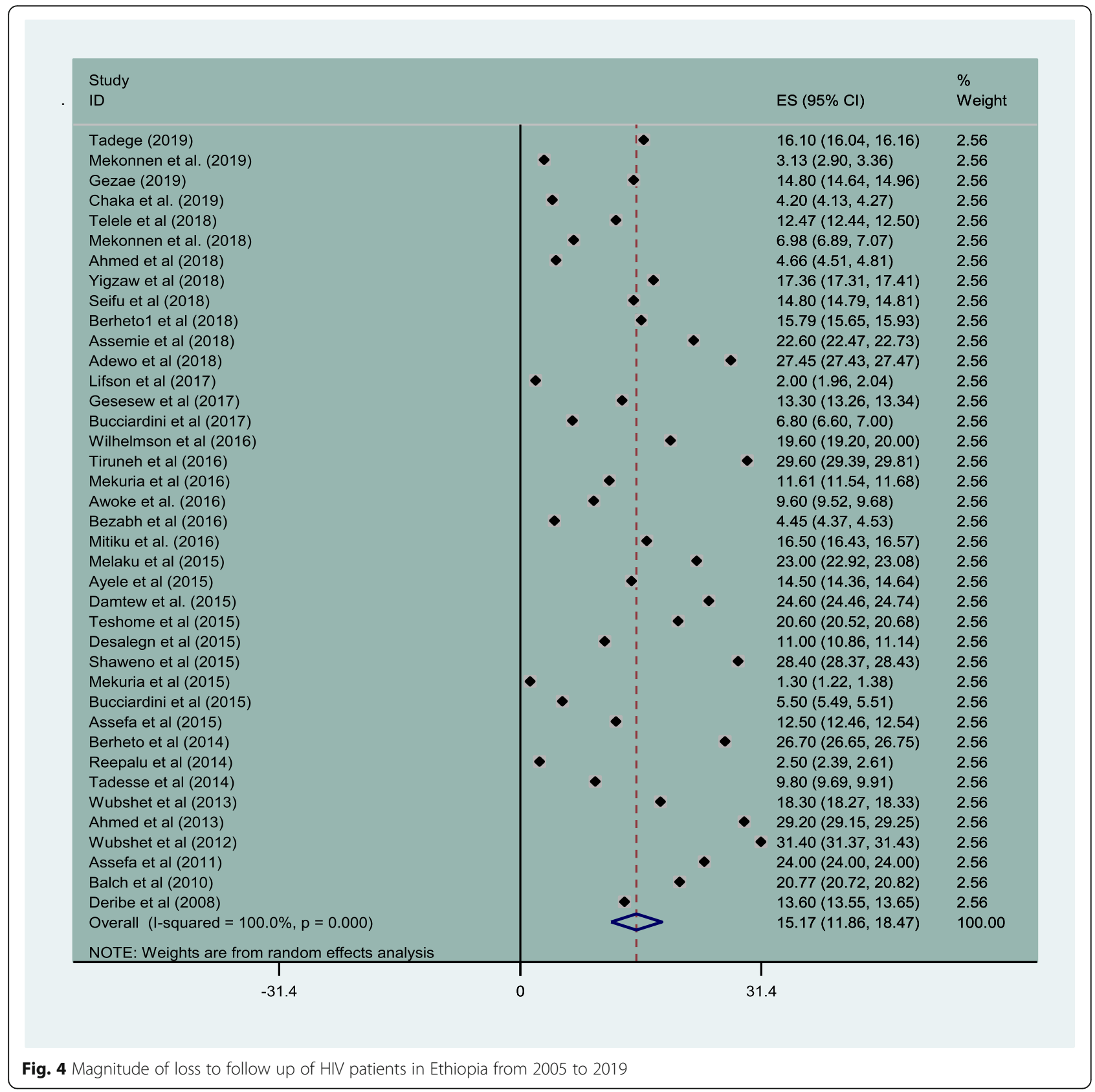

contrary result one as higher death rate in health centers than in hospitals and other is vice versa $[37,54]$. The pooled odds ratio indicated that there is no difference on level of retention based on health facility (OR, 1.23, 95\% CI, 0.58-2.62) Table 4.

\section{Discussion}

This systematic review and meta-analysis investigated available evidence on the magnitude and associated factors of HIV patient retention and attrition in clinical care in Ethiopia.
The study indicated that the pooled prevalence of HIV patients' clinical retention was 70.65\%; and attritions was $15.17 \%$ loss to follow up, $6.75 \%$ death, and $11.17 \%$ transfer out. Furthermore, the incidence of loss to follow up was 13.79 person years of observation. Factors such as being currently unmarried, non-disclosed of HIV status, history of poor drug adherence, poor functional status, presence of opportunistic infections, lower BMI, substance use, lower hemoglobin and advanced WHO clinical stages were significantly associated with patient attrition. 


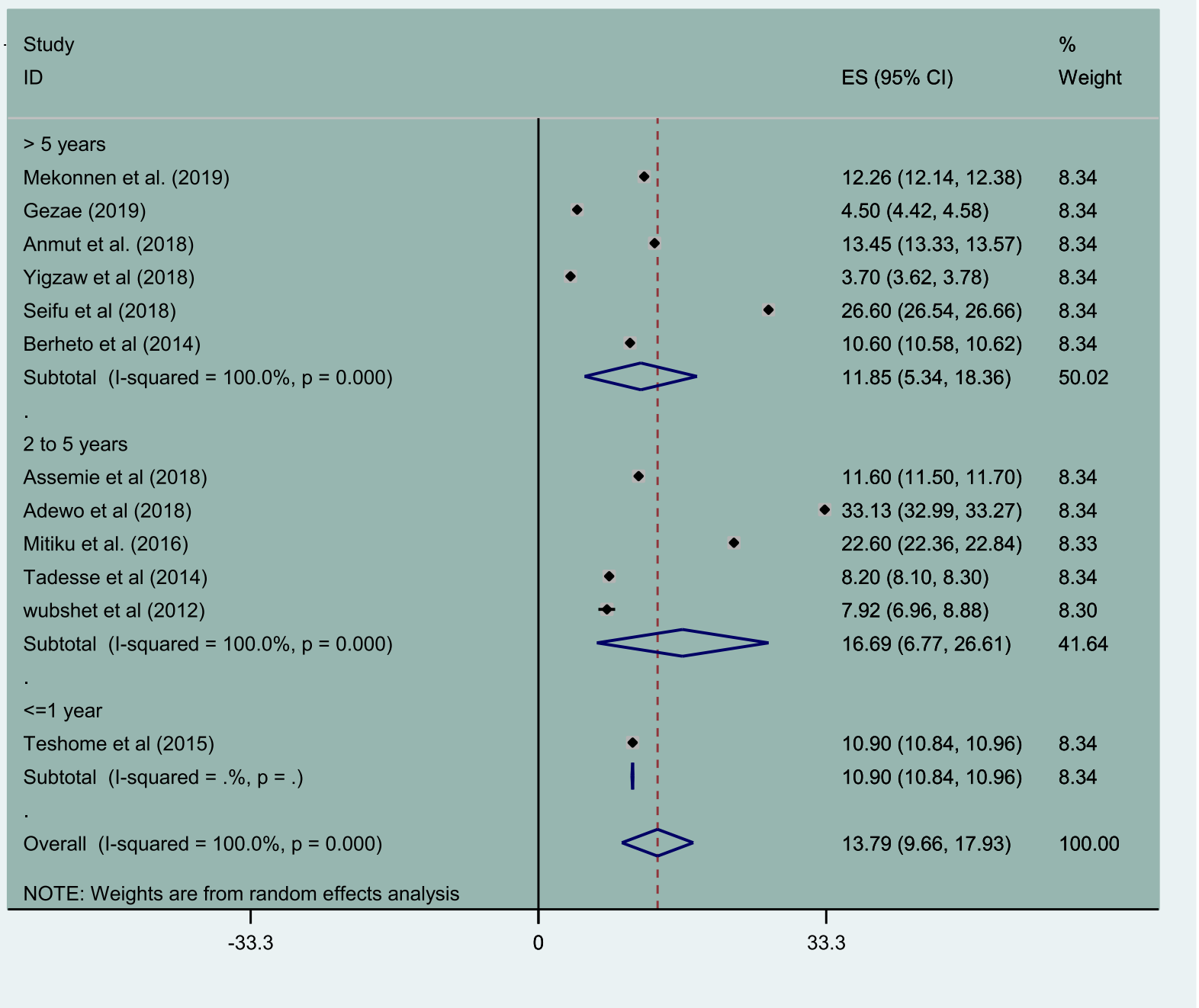

Fig. 5 Incidence rate of loss to follow up among HIV patient on treatment in Ethiopia

Levels of HIV patient retention in antiretroviral treatment program in Ethiopia (70.65\%) was comparable to the report from a study in India (70.7\%) [64]. On the other hand, it was lower than patient retention in Asia (80\%) [4], Sub Saharan Africa (77.5\%) and Cape Town, South Africa 94\% [65-67], Anambra, Nigeria (80\%) [68], KwaZulu-Natal, South Africa (77.5\%) [69], Khayelitsha,
South Africa (85.9\%) [5] and Southeastern United States (91.7\%) [70]. This could be explained by the inclusion in our analysis of studies with longer follow-up periods. The longer the follow up period the lower the rates of clinical retention [69]. In addition, other possible reasons for the observed differences include the fact that countries have different levels of infrastructure, HIV burden,

Table 2 Summery of retention and attrition rates among HIV patients attending clinical care in Ethiopia from 2005 to 2019

\begin{tabular}{llll}
\hline Attrition rate & No. of studies & Sample & Magnitude at 95\% Cl \\
\hline Retention rate & 32 & 492,356 & $70.65(68.19,73.11)$ \\
Magnitude of Loss to follow up & 39 & 147,896 & $15.17(11.86,18.47)$ \\
Incidence of Loss to follow up & 12 & 11,777 & $13.79 / 100$ person years of observation $(9.66,17.93)$ \\
Death & 29 & 105,699 & $6.75(6.22,7.27)$ \\
Transfer out & 20 & 34,565 & $11.17(7.12,15.21)$ \\
\hline
\end{tabular}




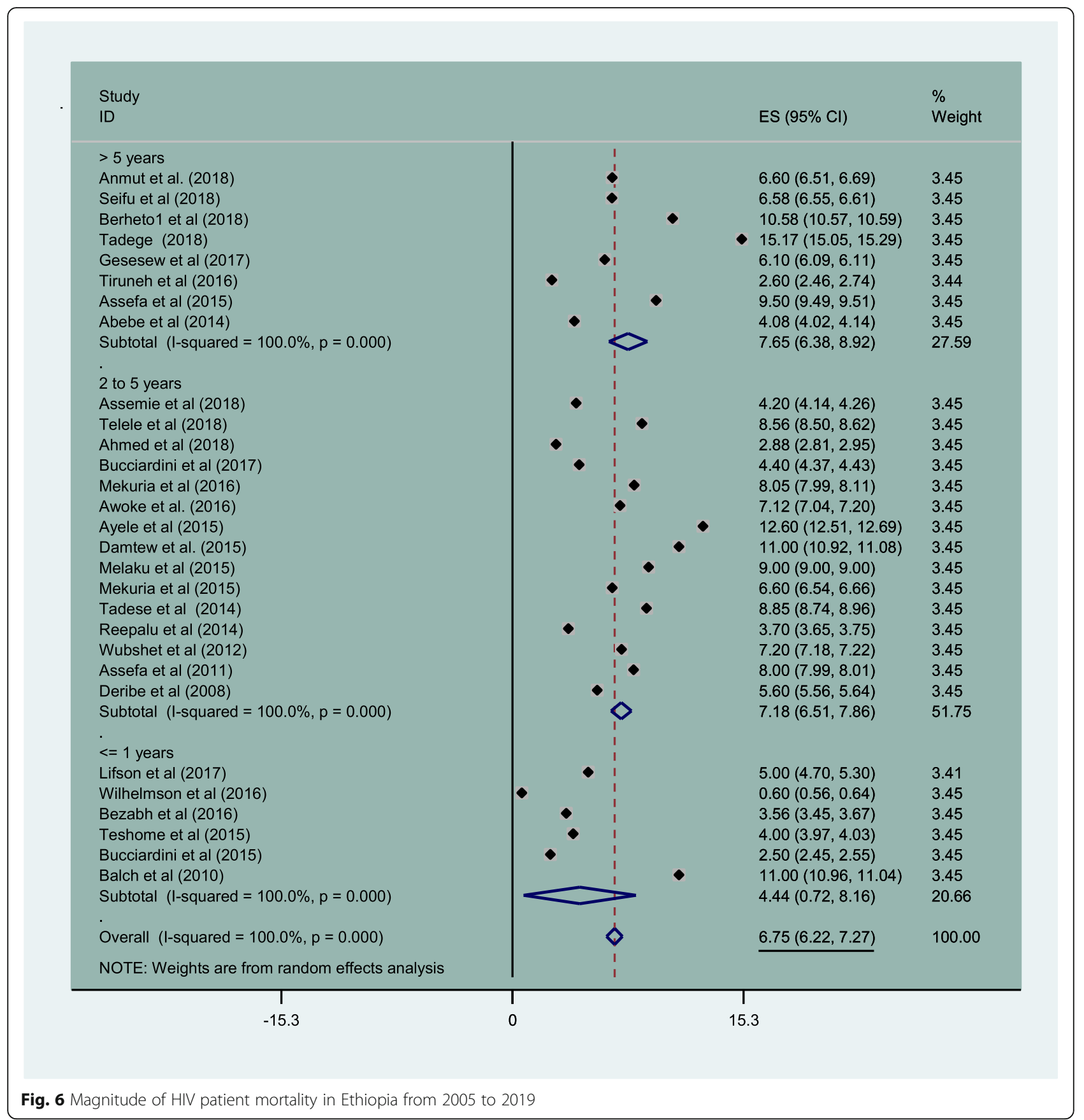

and HIV associated stigma that can cause loss to follow and transfer out to other health facilities [71].

On the other hand, the level of patient retention in this study is higher than that observed studies conducted among HIV infected patients from Africa (65\%), Latin America and Caribbean (64\%) [4], Asia-Pacific Region [72], Tanzania (25\%) [73] and South Africa [74]. In Africa, Asia, and Latin America that the value ranged from 3.1 to $45.1 \%$ [75]. The reason might be the differences in cut off point for loss to follow up (LTFU) and treatment eligibility criteria of the latter two studies. Now a days, immediate initiation of ART following HIV positive test result may contributed for good patient retention [66, 74, 76-78]. This might be due to test and treat strategy is effective in patient retention since it decreases the chance of loss to follow up from determining treatment eligibility to adherence preparation $[79,80]$. 


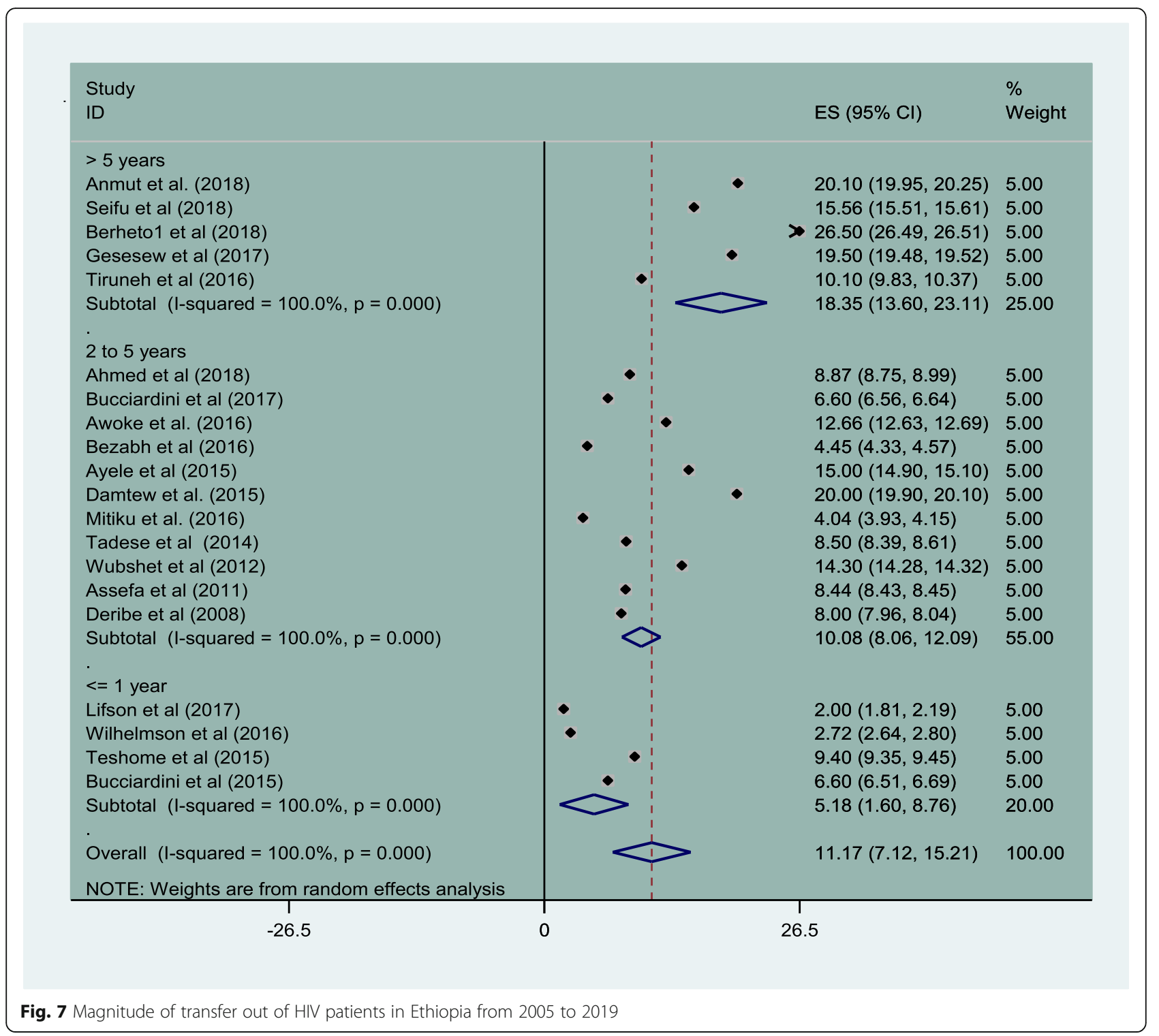

In this study, rate of HIV patients lost to follow up, death and transfer out is similar with study report form India [64] but higher than study from Australia and Asia [81]. Loss to follow up was the major cause of attrition, followed by death and transfer out. This is in line with a previous systematic review in sub-Saharan Africa [67].

On the other hand, rate of lost to follow up (13.79 per 100 person years of observation) was lower than observed from previous studies from Asia Pacific region (21.4 person years of observation) [72], Malawi (26 and 48 per 100 person years of observation for pre-ART and ART patients respectively), Guinea-Bissau (51.1 per 100 person-years of observation) [82] and study conducted among children in Ethiopia 29.7\% [7]. The reason can be due to difference of study population and the current study was composite of both earlier and recent times study findings while the previous study was conducted at the beginning of the treatment. Moreover patient retention was better in Asia than Africa from previous study [61] that reflects country specific difference in terms of patients retention. Moreover, the pooled death rate was $6.75 \%$ which is lower than previous systematic review $5-40 \%$ of death in Ethiopia [83]. The variation may be due to small sample size in the previous study and different time of follow up.

Our review identified a number of socio-demographic and clinical factors that could be targets for future interventions. It is indicated that currently unmarried people 
Table 3 Socio-demographic factors associated with HIV/AIDS patients' attrition from care in Ethiopia (2005-2019)

\begin{tabular}{|c|c|c|c|c|c|}
\hline Variables & $\mathrm{No}^{*}$ & Sample & OR $(95 \% \mathrm{Cl})$ & $\mathrm{I}^{2}(\%)$ & $P$-value \\
\hline \multicolumn{6}{|l|}{ Age in years } \\
\hline $18-24$ & 8 & 12,482 & 1 & 99 & $<0.001$ \\
\hline$>24$ & & & $0.88(0.27-2.89)$ & & \\
\hline \multicolumn{6}{|l|}{ Sex } \\
\hline Female & 18 & 33,424 & 1 & 82.1 & $<0.001$ \\
\hline Male & & & $1.12(0.97-5.45)$ & & \\
\hline \multicolumn{6}{|l|}{ Marital status } \\
\hline married & 13 & 18,911 & 1 & 90.8 & $<0.001$ \\
\hline Not married & & & $1.52(1.15-2.01)^{* *}$ & & \\
\hline \multicolumn{6}{|l|}{ Employment status } \\
\hline Employed & 3 & 1887 & 1 & 70 & 0.036 \\
\hline Not employed & & & $1.27(0.86-1.88)$ & & \\
\hline \multicolumn{6}{|l|}{ Residence } \\
\hline Urban & 2 & 12,735 & 1 & 93.3 & $<0.001$ \\
\hline Rural & & & $0.87(0.43-1.78)$ & & \\
\hline \multicolumn{6}{|l|}{ Education } \\
\hline Educated & 8 & 6016 & 1 & 96.7 & $<0.001$ \\
\hline Not educated & & & $2.21(0.90-5.45)$ & & \\
\hline \multicolumn{6}{|l|}{ Disclosure status } \\
\hline Disclosed & 2 & 2008 & 1 & 71.1 & 0.063 \\
\hline Not disclosed & & & $6.36(3.58-11.29)^{* *}$ & & \\
\hline \multicolumn{6}{|l|}{ Substance use } \\
\hline Yes & 2 & 815 & 1 & 75.5 & 0.044 \\
\hline No & & & $0.41(0.17-0.98)^{* *}$ & & \\
\hline
\end{tabular}

No*---stands for numbers of articles

**Significant at $p$-value less than 0.05

(never married, separated, divorced and widowed) were 1.52 times more likely not to be retained in care. This is similar with a study in South Africa that reported women without regular partner were not retained in clinical care [69]. This might be because of married people get support from their spouse to adhere to their treatment. Likewise, those who did not disclose their HIV status to someone were 6.36 times more likely not to be retained in care. This can be explained by the fact that those who disclosed their sero-status can get support from someone who knew the HIV status and this facilitates regular treatment attendance. This might be due to people who had perceived HIV related stigma are more likely to experience treatment attrition [13] . Therefore, partner testing, HIV status disclosure and mutual support are important components of HIV intervention $[3,84]$. In contrast to these findings, one study in Nigeria showed that married women were poor in clinical retention [68]. These differences may be due to difference by cultural practices and the attitude of people on the role of gender in both countries.

Substance abuse and mental distress have negative effects on HIV patient retention in clinical care. This finding is in line with a systematic review in developing countries [85]. This might be due to poor drug adherence as a result of distressed mental status. Retention in care was significantly higher in patients treated by mental health trained healthcare workers [23]. This can be explained by the fact that the decision making ability of patients abusing substances is altered and this facilitates poor treatment adherence [13]. Inline to this, the previous studies also reported that patients with no bereavement concern were less likely to experience loss to follow up while patients with mental status not at ease were at increased risk of defaulting from treatment [50,51].

It was evidenced that advanced clinical stage such as poor baseline functional status, WHO clinical stage III or IV, suboptimal ART adherence, presence of one or more opportunistic infections and being underweight had higher risk of patient attrition. Such findings are similar to findings from studies in Ethiopia [83], Malawi ([86], Guinea-Bissau [82] and Asia Pacific region [72]. The reasons for patients to be non-adherent were forgetfulness, side effects, feeling sick and running out of medication [87].

\section{Limitation of the study}

Original articles used different length of follow up period that had variable outcomes of attrition. Moreover, studies conducted across different treatment guidelines revision may affect patient retention and treatment outcome.

\section{Conclusion}

About two third of HIV patients were retained in care. The most common cause of attrition among HIV positive people in Ethiopia were loss to follow up, transfer out and death respectively. It can be concluded that Ethiopia has long to walk to achieve the minimum targets of patient retention achieved by most of low income countries. There were increased attrition rate for longer period of follow up that need due attention from clinicians. Due to change of treatment eligibility criteria from time to time and varying definitions of loss to follow up, it is necessary to reconsider the definitions of LTFU. Moreover, tracing studies are necessary to rule out final destination of loss to follow up patients. Social support is necessary for all HIV patients and encouraging disclosure to family members. This also implied HIV patients require mental health interventions in addition to the medical model of treatment. Patients with poor drug adherence, advanced HIV disease stage, opportunistic 
Table 4 Clinical factors associated with HIV/AIDS patients' attrition from care in Ethiopia (2005-2019)

\begin{tabular}{|c|c|c|c|c|c|}
\hline Variables & $\mathrm{No}^{*}$ & Sample & OR $(95 \% \mathrm{Cl})$ & $1^{2}(\%)$ & $P$-value \\
\hline \multicolumn{6}{|l|}{ ART adherence } \\
\hline Good & 5 & 6080 & 1 & 98.1 & $<0.001$ \\
\hline Poor/fair & & & $6.60(1.41-30.97)^{* *}$ & & \\
\hline \multicolumn{6}{|l|}{ Functional status } \\
\hline Working & 12 & 9954 & 1 & 92.1 & $<0.001$ \\
\hline Ambulatory/bedridden & & & $2.11(1.33-3.34)^{* *}$ & & \\
\hline \multicolumn{6}{|l|}{ Opportunistic disease } \\
\hline Yes & 8 & 7574 & 1 & 94.3 & $<0.001$ \\
\hline No & & & $0.52(0.30-0.90)^{* *}$ & & \\
\hline Recorded appointment & & & & & $<0.001$ \\
\hline Yes & 2 & 2518 & 1 & 97.6 & \\
\hline No & & & $0.7(0.17-2.88)$ & & \\
\hline \multicolumn{6}{|l|}{ BMl } \\
\hline Normal $(\geq 18.5)$ & 4 & 2260 & 1 & 70.7 & 0.017 \\
\hline Underweight (< 18.5) & & & $2.21(1.45-3.39)^{* *}$ & & \\
\hline \multicolumn{6}{|l|}{ side effects } \\
\hline Yes & 2 & 1196 & 1 & 98.8 & $<0.001$ \\
\hline No & & & $0.83(0.03-26.98)$ & & \\
\hline \multicolumn{6}{|l|}{$\mathrm{INH}$} \\
\hline Took INH & 4 & 2275 & 1 & 97.7 & $<0.001$ \\
\hline Not took INH & & & $3.42(0.57-20.51)$ & & \\
\hline \multicolumn{6}{|l|}{ Health facility } \\
\hline Health center & 2 & 11,717 & 1 & 84.5 & 0.011 \\
\hline Hospital & & & $1.23(0.58-2.62)$ & & \\
\hline \multicolumn{6}{|l|}{ Baseline WHO stage } \\
\hline | and || & 12 & 21,509 & 1 & 92 & $<0.001$ \\
\hline III and IV & & & $1.85(1.36-2.51)^{* *}$ & & \\
\hline \multicolumn{6}{|l|}{ Baseline CD4 level } \\
\hline$<200$ & 8 & 19,134 & 1 & 98.3 & $<0.001$ \\
\hline$\geq 200$ & & & $1.09(0.49-2.41)$ & & \\
\hline \multicolumn{6}{|l|}{ Hemoglobin } \\
\hline Anemic $(<10 \mathrm{~g} / \mathrm{ml})$ & 2 & 815 & 1 & 0 & 0.35 \\
\hline Normal $(\geq 10 \mathrm{~g} / \mathrm{ml})$ & & & $0.29(0.20-0.42)^{* *}$ & & \\
\hline
\end{tabular}

$\mathrm{No}^{*---s t a n d s}$ for numbers of articles, ${ }^{* *}$ significant at $p$-value $<0.05$

infection, poor functional status (ambulatory or bedridden), underweight and anemic patients need special attention that includes adequate adherence preparation and nutritional intervention. In general it was evidenced that number of socio-demographic determinants prone patients for loss to follow up while the clinical factors leads to death. Hence, in order to achieve the desired level of patient retention in clinical care, a comprehensive interventions which are targeted at sociodemographic, clinical, laboratory and behavioral factors is necessary.

\section{Supplementary information}

Supplementary information accompanies this paper at https://doi.org/10. 1186/s12879-020-05168-3.

Additional file 1: Table S1. Quality assessment of articles for attrition of HIV positive people in care and its determinants in Ethiopia (20052019).

\section{Abbreviations}

AIDS: Acquired Immunodeficiency Syndrome; Cl: Confidence Interval; HIV: Human immunodeficiency virus; LTF: Loss to Follow up; WHO: World Health Organization

\section{Acknowledgments}

We acknowledged Pan African University (PAU) for funding and we would like to acknowledge all authors of the primary papers.

\section{Authors' contributions}

NAM and OAA conceived the study, contributed to the study design, data collection, data analysis, interpretation of results, and NAM was primarily responsible for writing the manuscript. MAO assisted with statistical analysis. YB contributed to the study conception, data interpretation, and editing of the manuscript. All authors read and approved the final manuscript.

\section{Funding}

This study was supported by the Pan African University (PAU), a continental initiative of the African Union Commission (AU), Addis Ababa, Ethiopia, as part of the Ph.D. program in Reproductive Health Sciences. NAM received the funding from PAU. The University had no role in the study design, data collection and analysis, decision to publish, or preparation of the manuscript.

Availability of data and materials

Data from this manuscript is available upon request by contacting the corresponding author.

Ethics approval and consent to participate

Not applicable.

\section{Consent for publication}

Not applicable.

\section{Competing interests}

The authors declare that they have no competing interests.

\section{Author details}

'Department of Public Health, College of Health Sciences, Debre Markos University, Debre Markos, Ethiopia. ${ }^{2}$ Pan African University, Life and Earth Sciences Including Health and Agriculture Institute (PAULESI), University of Ibadan, Ibadan, Nigeria. ${ }^{3}$ Department of Obstetrics and Gynecology,

University College Hospital, University of Ibadan, Ibadan, Nigeria.

${ }^{4}$ Department of Epidemiology, Addis Continental Institute of Public Health, Addis Ababa, Ethiopia.

Received: 7 December 2018 Accepted: 17 June 2020

Published online: 22 June 2020

\section{References}

1. (UNAIDS), J.U.N.P.o.H.A, Joint United Nations Programme on HIV/AIDS (UNAIDS) http://aidsinfo.unaids.org. Accessed 16 Aug 2017. 2017.

2. HIV/AIDS, J.U.N.P.O. Ending AIDS: Progress Towards the 90-90-90 Targets. Geneva: Joint United Nations Programme on HIV. AIDS; 2017.

3. Ethiopia, F.M.o.H., National guidelines for comprehensive HIV prevention, care and treatment, A.A.M.o. Health. 2017.

4. Fox MP. Retention of adult patients on antiretroviral therapy in low-and middle-income countries: systematic review and meta-analysis 2008-2013. J Acquir Immune Defic Syndr (1999). 2015;69(1):98.

5. Wilkinson $L$, et al. Outcomes from the implementation of a counselling model supporting rapid antiretroviral treatment initiation in a primary healthcare clinic in Khayelitsha, South Africa. Southern African J HIV Med. 2015;16(1):1-7. 
6. Abuogi LL, Smith C, McFarland EJ. Retention of HIV-infected children in the first 12 months of anti-retroviral therapy and predictors of attrition in resource limited settings: a systematic review. PLoS One. 2016;11(6): e0156506.

7. Westerlund $E_{\text {, et }}$ al. Pre-ART retention in care and prevalence of tuberculosis among HIV-infected children at a district hospital in southern Ethiopia. BMC Pediatr. 2014;14(1):250

8. Ahmed I, et al. Predictors of loss to follow-up before HIV treatment initiation in Northwest Ethiopia: a case control study. BMC Public Health. 2013;13(1): 867.

9. Assefa $Y$, et al. Performance of the antiretroviral treatment program in Ethiopia, 2005-2015: strengths and weaknesses toward ending AIDS. Int J Infect Dis. 2017;60:70-6.

10. Tiruneh YM, et al. Retention in care among HIV-infected adults in Ethiopia, 2005-2011: a mixed-methods study. PLoS One. 2016;11(6):e0156619.

11. Bezabhe WM, et al. Barriers and facilitators of adherence to antiretroviral drug therapy and retention in care among adult HIV-positive patients: a qualitative study from Ethiopia. PLoS One. 2014;9(5):e97353.

12. Assefa $Y$, et al. Scaling up antiretroviral treatment and improving patient retention in care: lessons from Ethiopia, 2005-2013. Glob Health. 2014;10(1): 43.

13. Gesesew HA, et al. Discontinuation from antiretroviral therapy: a continuing challenge among adults in HIV care in Ethiopia: a systematic review and meta-analysis. PLoS One. 2017;12(1):e0169651.

14. Moher D, et al. Preferred reporting items for systematic reviews and metaanalyses: the PRISMA statement. Ann Intern Med. 2009;151(4):264-9.

15. Munn Z, et al. Methodological guidance for systematic reviews of observational epidemiological studies reporting prevalence and cumulative incidence data. Int J Evidence-Based Healthcare. 2015;13(3):147-53.

16. Seifu W, Ali W, Meresa B. Predictors of loss to follow up among adult clients attending antiretroviral treatment at Karamara general hospital, Jigjiga town, eastern Ethiopia, 2015: a retrospective cohort study. BMC Infect Dis. 2018; 18(1):280.

17. Assemie MA, Muchie KF, Ayele TA. Incidence and predictors of loss to follow up among HIV-infected adults at Pawi general hospital, Northwest Ethiopia: competing risk regression model. BMC Res Notes. 2018;11(1):287.

18. Abebe $\mathrm{N}$, et al. Survival status of hiv positive adults on antiretroviral treatment in Debre Markos referral hospital, Northwest Ethiopia: retrospective cohort study. Pan African Med J. 2014;17:88.

19. Peters $\mathrm{J}$, et al. Assessing publication bias in meta-analyses in the presence of between-study heterogeneity. J Royal Stat Soc. 2010;173(3):575-91.

20. Duval S, Tweedie R. A nonparametric "trim and fill" method of accounting for publication bias in meta-analysis. J Am Stat Assoc. 2000;95(449):89-98.

21. Higgins JP, et al. Measuring inconsistency in meta-analyses. BMJ. 2003; 327(7414):557.

22. Molla Yigzaw GD, Tesema C. Incidence and predictors of loss to-follow- up among HIV positive adults on antiretvoviral theraphy at Debre Marcos referral Hospital, Northwest, Ethiopia, 2018: a retrospective follow up study, in public health. Debre Markos; 2018.

23. Berheto $\mathrm{TM}$, et al. Body and mind: retention in antiretroviral treatment care is improved by mental health training of care providers in Ethiopia. BMC Public Health. 2018;18(1):896.

24. Takele A, t. M, Woiraw W. TIME TO LOST FOLLOW UP AND ITS PREDICTORS AMONG ADULT PATIENTS RECEIVING ANTIRETROVIRAL THERAPY IN BICHENA HEALTH CENTER RETROSPECTIVE: COHORT STUDY, 2018, IN Public healht. Debre markos: Debre Markso University; 2018.

25. Adewo TS, Asefa H, Gesesew HA. Time to attrition and factors associated among adults enrolled in pre-anti-retroviral therapy care in Tepi General Hospital, Ethiopia. Int J Health Med. 2018;3(2):6-13.

26. Gesesew HA, et al. Prevalence, trend and risk factors for antiretroviral therapy discontinuation among HIV-infected adults in Ethiopia in 20032015. PLoS One. 2017;12(6):e0179533.

27. Wilhelmson S, et al. Retention in care among HIV-positive patients initiating second-line antiretroviral therapy: a retrospective study from an Ethiopian public hospital clinic. Glob Health Action. 2016;9(1):29943.

28. Mitiku I, et al. Factors associated with loss to follow-up among women in option B+ PMTCT programme in Northeast Ethiopia: a retrospective cohort study. J Int AIDS Soc. 2016;19(1):20662.

29. Shaweno T, Shaweno D. When are patients lost to follow-up in preantiretroviral therapy care? A retrospective assessment of patients in an Ethiopian rural hospital. Infect Dis Poverty. 2015;4(1):27.
30. Melaku Z, et al. Characteristics and outcomes of adult Ethiopian patients enrolled in HIV care and treatment: a multi-clinic observational study. BMC Public Health. 2015;15(1):462.

31. Mekuria LA, et al. Retention in HIV care and predictors of attrition from care among HIV-infected adults receiving combination anti-retroviral therapy in Addis Ababa. PLoS One. 2015;10(6):e0130649.

32. Assefa $Y$, et al. Brief report: long-term outcomes and their determinants in patients on antiretroviral treatment in Ethiopia, 2005/6-2011/12 a retrospective cohort study. JAIDS J Acquir Immune Defic Syndr. 2015;70(4) 414-9.

33. Tadesse K, Fisiha H. Predictors of loss to follow up of patients enrolled on antiretroviral therapy: a retrospective cohort study. J AIDS Clin Res. 2014; 5(393):2.

34. Reepalu A, et al. High rates of virological suppression in a cohort of human immunodeficiency virus-positive adults receiving antiretroviral therapy in ethiopian health centers irrespective of concomitant tuberculosis. In Open forum infectious disease. America: Oxford University Press; 2014.

35. Berheto TM, Haile DB, Mohammed S. Predictors of loss to follow-up in patients living with HIV/AIDS after initiation of antiretroviral therapy. N Am J Med Sci. 2014;6(9):453.

36. Assefa $Y$, et al. Outcomes of antiretroviral treatment program in Ethiopia: retention of patients in care is a major challenge and varies across health facilities. BMC Health Serv Res. 2011;11(1):81.

37. Balcha TT, Jeppsson A. Outcomes of antiretroviral treatment: a comparison between hospitals and health centers in Ethiopia. J Int Assoc Phys AIDS Care. 2010;9(5):318-24.

38. Mekonnen $\mathrm{N}$, et al. Incidence and predictors of loss to follow-up among HIV infected adults after initiation of first line anti-retroviral therapy at University of Gondar comprehensive specialized hospital Northwest Ethiopia, 2018: retrospective follow up study. BMC Res Notes. 2019;12(1):111.

39. Gezae KE, Abebe HT, Gebretsadik LG. Incidence and predictors of LTFU among adults with TB/HIV co-infection in two governmental hospitals, Mekelle, Ethiopia, 2009-2016: survival model approach. BMC Infect Dis. 2019;19(1):107.

40. Chaka TE, Abebe TW, Kassa RT. Option B+ prevention of mother-to-child transmission of HIV/AIDS service intervention outcomes in selected health facilities, Adama town, Ethiopia. HIV/AIDS (Auckland, NZ). 2019;11:77.

41. Tadege M. Predictors associated with HIV/AIDS patients dropout from antiretroviral therapy at Mettu Karl Hospital, Southwest Ethiopia. BMC Res Notes. 2019;12(1):232.

42. Awoke $T$, et al. Modeling outcomes of first-line antiretroviral therapy and rate of CD4 counts change among a cohort of HIV/AIDS patients in Ethiopia: a retrospective cohort study. PLoS One. 2016;11(12):e0168323.

43. Ayele $\mathrm{W}$, et al. Treatment outcomes and their determinants in HIV patients on anti-retroviral treatment program in selected health facilities of Kembata and Hadiya zones, southern nations, nationalities and peoples region, Ethiopia. BMC Public Health. 2015;15(1):826.

44. Damtew B, Mengistie B, Alemayehu T. Survival and determinants of mortality in adult HIV/Aids patients initiating antiretroviral therapy in Somali Region, Eastern Ethiopia. Pan African Med J. 2015;22(1):138.

45. Tadege M. Time to death predictors of HIV/AIDS infected patients on antiretroviral therapy in Ethiopia. BMC Res Notes. 2018;11(1):761.

46. Mekonnen $\mathrm{E}$, et al. Reasons and predictors for antiretroviral therapy change among HIV-infected adults at south West Ethiopia. BMC Res Notes. 2018; 11(1):351.

47. Ahmed A, et al. Incidence and determinants of tuberculosis infection among adult patients with HIV attending HIV care in north-East Ethiopia: a retrospective cohort study. BMJ Open. 2018;8(2):e016961.

48. Mekuria LA, et al. High level of virological suppression among HIV-infected adults receiving combination antiretroviral therapy in Addis Ababa, Ethiopia. Antivir Ther. 2016;21:385-96.

49. Megerso A, et al. Predictors of loss to follow-up in antiretroviral treatment for adult patients in the Oromia region, Ethiopia. HIV/AIDS (Auckland, NZ). 2016:8:83.

50. Dessalegn M, Tsadik M, Lemma H. Predictors of lost to follow up to antiretroviral therapy in primary public hospital of Wukro, Tigray, Ethiopia: a case control study. J AIDS HIV Res. 2015;7(1):1-9.

51. Asefa $T$, et al. Determinants of defaulting from antiretroviral therapy treatment in Nekemte hospital, eastern Wollega zone, Western Ethiopia. Public Health Res. 2013:3(5):130-5. 
52. Deribe K, et al. Defaulters from antiretroviral treatment in Jimma university specialized hospital, Southwest Ethiopia. Tropical Med Int Health. 2008;13(3): 328-33.

53. Bucciardini $R$, et al. Predictors of attrition from care at 2 years in a prospective cohort of HIV-infected adults in Tigray, Ethiopia. BMJ Glob Health. 2017;2(3):e000325.

54. Teshome W, et al. Do loss to follow-up and death rates from ART care vary across primary health care facilities and hospitals in south Ethiopia? A retrospective follow-up study. HIV/AIDS (Auckland, NZ). 2015;7:167.

55. Bucciardini $R$, et al. Retention in care of adult HIV patients initiating antiretroviral therapy in Tigray, Ethiopia: a prospective observational cohort study. PLoS One. 2015;10(9):e0136117.

56. Lifson AR, et al. Implementation of a peer HIV community support worker program in rural Ethiopia to promote retention in care. J Int Assoc Providers AIDS Care (JIAPAC). 2017:16(1):75-80.

57. Bezabhe WM, et al. Antiretroviral adherence and treatment outcomes among adult Ethiopian patients. AIDS Care. 2016;28(8):1018-22.

58. Telele NF, et al. Baseline predictors of antiretroviral treatment failure and lost to follow up in a multicenter countrywide HIV-1 cohort study in Ethiopia. PLoS One. 2018;13(7):e0200505.

59. Wubshet $\mathrm{M}$, et al. Death and seeking alternative therapy largely accounted for lost to follow-up of patients on ART in Northwest Ethiopia: a community tracking survey. PLoS One. 2013;8(3):e59197.

60. Wubshet $\mathrm{M}$, et al. High loss to followup and early mortality create substantial reduction in patient retention at antiretroviral treatment program in north-West Ethiopia. Isrn aids. 2012;2012:721720.

61. Matthew P, Fox D. 1,2,3 and Sydney Rosen MPA1,3, retention of adult patients on antiretroviral therapy in low-and middle-income countries: systematic review and meta-analysis 2008-2013. J Acquir Immune Defic Syndr. 2015;6(9):453.

62. Assefa $Y$, et al. How to improve patient retention in an antiretroviral treatment program in Ethiopia: a mixed-methods study. BMC Health Serv Res. 2014;14(1):45.

63. Lifson AR, et al. Barriers to retention in care as perceived by persons living with HIV in rural Ethiopia: focus group results and recommended strategies. $J$ Int Assoc Providers of AIDS Care (JIAPAC). 2013;12(1):32-8.

64. Mehta KG, et al. Drug adherence rate and loss to follow-up among people living with HIV/AIDS attending an ART Centre in a tertiary government Hospital in Western India. J Family Med Primary Care. 2016;5(2):266.

65. Fox MP, Rosen S. Patient retention in antiretroviral therapy programs up to three years on treatment in sub-Saharan Africa, 2007-2009: systematic review. Tropical Med Int Health. 2010;15:1-15.

66. du Toit E, et al. Missed opportunities for retention in pre-ART Care in Cape Town, South Africa. PLoS One. 2014;9(5):e96867.

67. Rosen S, Fox MP, Gill CJ. Patient retention in antiretroviral therapy programs in sub-Saharan Africa: a systematic review. PLoS Med. 2007;4(10):e298.

68. Umeokonkwo CD, et al. Retention in care and adherence to HIV and AIDS treatment in Anambra state Nigeria. BMC Infect Dis. 2019;19(1):654.

69. Larmarange J. Retention in care trajectories of HIV-positive individuals participating in a universal test-and-treat program in rural South Africa (ANRS 12249 TasP trial)-Joseph Larmarange; 2019.

70. Kay ES, Lacombe-Duncan A, Pinto RM. Predicting Retention in HIV Primary Care: Is There a Missed Visits Continuum Based on Patient Characteristics? AIDS and Behavior. 2019;23:1-7.

71. Gesesew HA, et al. Significant association between perceived HIV related stigma and late presentation for HIV/AIDS care in low and middle-income countries: a systematic review and meta-analysis. PLoS One. 2017;12(3): e0173928.

72. Zhou J, et al. Loss to followup in HIV-infected patients from Asia-Pacific region: results from TAHOD. AIDS Res Treatment. 2012;2012:375217.

73. Makunde $\mathrm{WH}$, et al. Lost to follow up and clinical outcomes of HIV adult patients on antiretroviral therapy in care and treatment centres in Tanga City, north-eastern Tanzania. Tanzania J Health Res. 2012;14(4):250-6.

74. Bor J, et al. Treatment eligibility and retention in clinical HIV care: a regression discontinuity study in South Africa. PLoS Med. 2017;14(11):e1002463.

75. Chi BH, et al. Universal definition of loss to follow-up in HIV treatment programs: a statistical analysis of 111 facilities in Africa, Asia, and Latin America. PLoS Med. 2011;8(10):e1001111.

76. Geng EH, et al. Failure to initiate antiretroviral therapy, loss to follow-up and mortality among HIV-infected patients during the pre-ART period in Uganda. J Acquir Immune Defic syndromes (1999). 2013;63(2):e64.
77. Mugglin C, et al. Loss to programme between HIV diagnosis and initiation of antiretroviral therapy in sub-Saharan Africa: systematic review and metaanalysis. Tropical Med Int Health. 2012;17(12):1509-20.

78. Kelly JD, et al. The majority of the pre-antiretroviral population who were lost to follow-up stopped their Care in Freetown, Sierra Leone: a 12-month prospective cohort study starting with HIV diagnosis. PLoS One. 2016;11(2): e0149584.

79. Rosen S, Fox MP. Retention in HIV care between testing and treatment in sub-Saharan Africa: a systematic review. PLoS Med. 2011;8(7):e1001056.

80. Jani IV, et al. Effect of point-of-care CD4 cell count tests on retention of patients and rates of antiretroviral therapy initiation in primary health clinics: an observational cohort study. Lancet. 2011;378(9802):1572-9.

81. Guy R, et al. Antiretroviral treatment interruption and loss to follow-up in two HIV cohorts in Australia and Asia: implications for 'test and treat'prevention strategy. AIDS Patient Care STDs. 2013:27(12):681-91.

82. Hønge $B \mathrm{~L}$, et al. Loss to follow-up occurs at all stages in the diagnostic and follow-up period among HIV-infected patients in Guinea-Bissau: a 7-year retrospective cohort study. BMJ Open. 2013;3(10):e003499.

83. Biset Ayalew M. Mortality and its predictors among HIV infected patients taking antiretroviral treatment in Ethiopia: a systematic review. AIDS Res Treatment. 2017;2017:5415298.

84. Layer EH, et al. Multi-level factors affecting entry into and engagement in the HIV continuum of Care in Iringa, Tanzania. PLoS One. 2014;9(8):e104961.

85. Bulsara SM, Wainberg ML, Newton-John TR. Predictors of adult retention in HIV care: a systematic review. AIDS Behav. 2018;22(3):752-64.

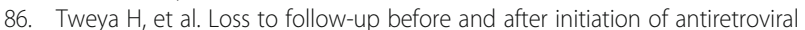
therapy in HIV facilities in Lilongwe, Malawi. PloS One. 2018;13(1):e0188488.

87. Tegegne AS, Ndlovu P, Zewotir T. Factors affecting first month adherence due to antiretroviral therapy among HIV-positive adults at Felege Hiwot teaching and specialized hospital, North-Western Ethiopia; a prospective study. BMC Infect Dis. 2018;18(1):83.

\section{Publisher's Note}

Springer Nature remains neutral with regard to jurisdictional claims in published maps and institutional affiliations.

\section{Ready to submit your research? Choose BMC and benefit from:}

- fast, convenient online submission

- thorough peer review by experienced researchers in your field

- rapid publication on acceptance

- support for research data, including large and complex data types

- gold Open Access which fosters wider collaboration and increased citations

- maximum visibility for your research: over $100 \mathrm{M}$ website views per year

At BMC, research is always in progress.

Learn more biomedcentral.com/submissions 